\title{
A CLIMATOLOGY OF STRONG WIND EVENTS AT MCMURDO STATION, ANTARCTICA
}

\author{
SHEEBA NETTUKANDY CHENOLI*, JOHN TURNER ${ }^{1}$, AZIZAN ABU SAMAH
}

National Antarctic Research Centre, Institute of Postgraduate Studies, University of Malaya, 50603 KUALA LUMPUR, Malaysia

${ }^{1}$ Permanent affiliation: British Antarctic Survey, Cambridge, UK

Short Title: CHENOLI ET AL: A CLIMATOLOGY OF STRONG WIND EVENTS AT MCMURDO STATION

07 September 2012

\footnotetext{
* Correspondence to: Sheeba Nettukandy Chenoli, National Antarctic Research Centre, Institute of Postgraduate Studies, University of Malaya, 50603 KUALA LUMPUR, Malaysia; e-mail: sheeba@um.edu.my
} 


\begin{abstract}
The first climatology of strong wind events (SWEs) at McMurdo Station, Antarctica based on the in-situ observations and reanalysis fields is presented. SWEs occur throughout the year, but with a minimum during the summer. They are associated with negative mean sea level pressure (MSLP) and upper height anomalies across the Ross Sea/Ice Shelf, as well as positive temperature anomalies at the station. Wind directions during SWEs exhibit a bimodal distribution of $135-180^{\circ}$ and $45-90^{\circ}$. This distribution occurs because of the interaction of the predominantly southerly flow with the orography of Black and White Island and Minna Bluff. The east-northeast flow is associated with winds that are deflected around the orography, while the more southerly events have sufficient energy to override the barriers. The bimodal wind distribution is most common during the winter season since the southerly flow is stronger as a result of deeper cyclonic systems. SWEs also occur when there are large, positive MSLP anomalies at McMurdo Station as ridges of high pressure build from the interior and enhance the pressure gradient between the continental high and offshore lows. The interannual variability in the number of winter SWEs is large. Years with many SWEs are associated with a deep climatological low centred over the north eastern Ross Ice Shelf. Years with few winter SWEs have a weakened mid-tropospheric vortex over the Ross Ice Shelf. There are periods when the index of the E1 Niño-Southern Oscillation (ENSO) correlates with the number of SWEs. However, the links are not statistically significant in the longer term. A similar link was also observed between the Southern Annular Mode (SAM) and the interannual variability in the number of SWEs. The relationship was found to be stronger when the phase of ENSO and the SAM were the same.
\end{abstract}


KEY WORDS: Strong wind events; Antarctica; bimodal wind direction; interannual variability; mean sea level pressure; Southern Annular Mode; wind speed. 


\section{INTRODUCTION}

Strong wind events (SWEs) are an important feature of the Antarctic coastal region because of the part that they play in the general circulation of the high southern latitudes (Parish and Bromwich, 1998) and their effects on logistical operations. These events play a significant role in the heat budget of the troposphere over the Antarctica (van Lipzig et al., 2002, van As et al., 2007) and the surface mass balance through the transport of precipitation and snowdrift (van As et al., 2007). Blowing snow caused by the SWEs is also important for the safety of the aircraft operations. During the winter, wind speeds as low as $7 \mathrm{~ms}^{-1}$ can result in blowing snow (Holmes et al., 2000). The Ross Sea region is logistically accessible by a number of international Antarctic programmes managed by the United States of America (USA), France, Italy, and New Zealand. McMurdo Station, which is the logistic hub for the US Antarctic Program (USAP), is the largest scientific research programme in the Antarctic. Airfields near McMurdo Station handle intercontinental flights to and from Christchurch, New Zealand and intracontinental flight from the South Pole and other continental locations. There are over 700 flights to McMurdo Station each year and nearly 175 were aborted due to bad weather conditions (Lazzara, 2008). Figure 1(a) shows the map of Antarctica with the locations named in the text and Figure 1(b) shows the locations and the topographical features in the vicinity of McMurdo Station.

There have been a number of earlier studies into strong winds along the coastal regions of the Ross Sea (Figure 1(a)) based on satellite imagery (Breckenridge, 1985; Bromwich, 1989a, 1991, 1992; Bromwich et al., 1992; Bromwich \& Kurtz 1984; Carrasco and Bromwich, 1993; Kurtz \& Bromwich 1985). These studies showed that 
the events were due to the interaction of downslope katabatic flow with the depressions just to the north of the coastline in the circumpolar trough. The studies also showed the importance of topographic and synoptic modulation in the intensity of the katabatic wind. Observational studies, undertaken using an array of automatic weather stations (AWSs) (Breckenridge et al., 1993; Bromwich et al., 1993; Bromwich, 1989b) deployed on the Ross Ice Shelf mainly focused on case studies of katabatic and other SWEs. Some of the earlier observational studies have shown that the southwest corner of the Ross Sea region is an area of frequent cyclogenesis (Bromwich, 1991; Carrasco 1994; Carrasco and Bromwich 1993). Keable et al. (2002) and Simmonds et al. (2003) also found high cyclone density over the Ross Ice Shelf during winter and suggested that these were quasi-stationary features, which reflected localised interaction of the wind field with the Antarctic topography. Bromwich et al. (2011) showed that the Adélie Land coastal region is one of the most prominent cyclogenesis regions in the Southern Hemisphere. In the this study, using an automated cyclone-tracking scheme, they showed that these cyclones generally took an eastward track and spiralled southeastwards onto the Ross Ice Shelf and coastal Marie Byrd Land (Figure 1(a)). Therefore, it is possible that the number of SWEs affecting McMurdo Station is also dependant on the synoptic condition over the neighbouring area.

High-resolution, non-hydrostatic numerical models have been used to understand the wind flow around the Ross Island region (Figure 1(b) (Seefeldt et al., 2003, Monaghan et al., 2005) and these showed the importance of topographic features on the wind flow over the region. The archive of the numerical weather model forecasts from the Antarctic Mesoscale Prediction System (AMPS) from 2003 to 2005 were used to examine the seasonal and annual climate of the McMurdo Station area 
(Monaghan et al., 2005). The results of this study also highlighted the fact that the orography exerts an important influence on the near-surface wind field. However, the AMPS operational forecast archive over Antarctica only covers a short period from 2001 to the present. In addition, during the 10-year period (2001-2011), there have been a number of modifications to the configuration of the AMPS and the system currently uses the Polar WRF model rather than the Polar MM5 model that was utilised in the earlier period. Therefore, usage of the model output data to develop a climatology would create a number of biases due to the modifications in the model system.

The first climatology of SWEs at McMurdo Station based on the long term insitu observations and reanalysis data is presented in this paper. Here, a strong wind event (SWE) at McMurdo Station is defined as an occasion when the wind speed is Beaufort scale 6 and above which is 22 knots or $11.3 \mathrm{~m} / \mathrm{s}$. (Please refer http://www. metoffice.gov.uk/weather/marine/guide/beaufortscale.html). The selection of a minimum wind speed threshold was based on several factors, including the analysis of the long term REference Antarctic Data for Environmental Research (READER) dataset and the initiation of blowing snow. Based on several observational studies, King and Turner (1997) and Schwerdtfeger (1984) used a blowing snow threshold of $10 \mathrm{~ms}^{-1}$. Birnbaum et al (2010) and Van As et al (2007) defined SWEs at Kohnen station as events that have a minimum value of $10.8 \mathrm{~ms}^{-1}$. From the READER data from 1979 to 2005, it can be deduced that the annual mean wind speed for McMurdo Station is $5.2 \mathrm{~ms}^{-1}$. The selected threshold value also exceeds the criterion: the mean $+2 \times$ standard deviation value for the six hourly-mean values of a 28 -year period at McMurdo. The frequency distribution of 10-minute average wind speeds showed that wind speeds of up to $5 \mathrm{~ms}^{-1}$ have the highest frequency of occurrence $(61.36 \%)$ 
(See Table1). Wind speed between $11-15 \mathrm{~ms}^{-1}$ were found to be $5.99 \%$ of observed wind speeds whereas wind speeds between $16-20 \mathrm{~ms}^{-1}$ were only observed on $0.51 \%$ occasions. Table 1 shows that setting a higher threshold of wind speed in defining a SWE would reduce the number of SWEs significantly and severely limit the scope of the study.

This paper is organised as follows. The various forms of data used in the study are discussed in Section 2. Section 3 describes the general climatology of SWEs at McMurdo Station and the synoptic conditions under which they occur. The interannual variability in the number of SWEs and its possible linkage with the major modes of climate variability such as El Niño-Southern Oscillation (ENSO) and Southern Annular Mode (SAM) are discussed in Sections 4, 5 and 6. Section 7 considers the trends in the number of SWEs. The last section presents a discussion and the conclusions of the paper.

\section{DATA AND METHOD}

This study is mainly based on the in-situ surface observations from the Reference Antarctic Data for Environmental Research (READER) database created by the Scientific Committee on Antarctic Research (Turner et al., 2004) and automated weather station data (AWS). The READER data provide one of the longest, most reliable and consistent series of Antarctic surface climate data available. The data have been thoroughly quality controlled and where possible data obtained from the national programmes that maintain the stations. Many stations in Antarctica were established during the period of the International Geophysical Year (IGY). The McMurdo Station data are available from 1956 to 2007, however, the data used in this paper were limited 
to 1979 onwards as this is the period when satellite data are available and the reanalysis fields are reliable. McMurdo Station observations are taken at the McMurdo Weather Office, which is located in Building 165. The instrumentation is on the roof of that building. It should be noted that new buildings were constructed in the vicinity of the instrumentation site during the period 1979-2005. Therefore, it is possible to have some artificial biases in the long term trend calculations (Personal conversation Mathew Lazzara, University of Wisconsin). The 6 hourly surface observations were used for preparation of the climatology of SWEs. The surface meteorological parameters used for the study consisted of temperature, station pressure, mean sea level pressure (MSLP), wind speed and direction, MSLP anomaly and temperature anomaly. AWS observations from the University of Wisconsin Antarctic Automatic Weather Station (UWAAWS) program were also used in the study. There is a dense network of AWSs on the northwest Ross Ice Shelf. The AWS observations consist of ten-minute interval wind speed, wind direction, temperature, and atmospheric pressure. Radiosonde data from McMurdo Station, wind speed and wind directions are used to investigate the topographical influences on SWEs.

National Center for Environmental Prediction (NCEP) reanalysis fields (Kalnay et al., 1996) of many meteorological fields have been used to depict the synoptic conditions during the SWEs across the Ross Ice Shelf region. One of the motivations to use NCEP reanalysis data over European Centre for Medium-range Weather Forecasts (ECMWF) field is NCEP analysis data are freely available and downloadable whereas the ECMWF archive is accessible only to registered users in the member states and co-operating states. The NCEP reanalysis pressure field has been used to illustrate synoptic condition during the SWEs and the role of pressure anomaly 
on the occurrence of SWEs as well as to investigate the dependence of interannual variability of SWEs on the synoptic condition. The NCEP reanalysis data used in this study has proven to be reliable in capturing weather patterns and the synoptic climatology of the Southern Hemisphere (Bromwich et al., 2007). However, it should be noted that there are uncertainties in some aspects of the data sets. Pezza et al. (2008) pointed out that there is an artificial trend in MSLP in the reanalysis data which can affect the accuracy of the fields especially in the data-sparse regions of the Southern Hemisphere.

\section{THE CLIMATOLOGY OF SWES AT MCMURDO STATION BASED ON STATION OBSERVATIONS}

3(a) The annual distribution in the number of SWES

Based on the definition of SWEs noted earlier, the total number of SWEs in each month at McMurdo Station for the period 1979 to 2005 is given in the Figure 2. The figure shows that there is an extended broad winter maximum (June, July and August (JJA)) in the number SWEs and a minimum during summer (December, January and February (DJF)). The winter peak in number of SWEs is due to the increased storm activity over the Ross Sea during that season (Simmonds et al., 2003). The annual cycle in the number of SWEs exhibits a weak semi-annual oscillation with secondary peaks in March and September, which coincide with the southward migration and deepening of the circumpolar trough (Meehl, 1991). 


\section{3 (b) The bimodal distribution in the direction of SWEs.}

The McMurdo Station wind regime shows that the predominant direction for all seasons is from the north east and that there are no significant changes in the wind directions over the year. The wind rose for McMurdo Station shows that the strongest winds are always from the southeast to southwest quadrant i.e. from $135^{\circ}$ to $180^{\circ}$, except during summer and spring (September, October and November (SON) when a small number (less than 1\%) of SWEs are from an easterly direction. Figure 3 shows the distribution of directions of all SWEs from 1979 to 2005. The pattern clearly shows a bimodal distribution, with one group of SWEs clustered between $135^{\circ}$ to $180^{\circ}$ and a second group over $45^{\circ}$ to $90^{\circ}$.

In order to further investigate the splitting of wind direction between these two groups, the monthly wind direction was examined for all SWEs from 1979 to 2005 for each month (Figure 4). In December and January most of the SWEs are from the southeast sector. However, there were some instances of SWEs from a north easterly direction. At the end of summer (February) almost all SWEs were from south and south westerly direction and splitting in the direction was not present. The bimodal direction

of wind was found to be established in the autumn (March, April and May (MAM) and in the winter period. During late spring (November), the splitting of wind directions became less noticeable.

\section{3(c) The synoptic situations associated with the different wind directions}

The number of SWEs from 45 to $90^{\circ}(41 \%)$ is slightly more than from 135 to $180^{\circ}$ (34\%). However, the mean wind speeds of the events were observed to be higher than 
from the direction 135 to $180^{\circ}$ (southeasterly) $\left(15 \mathrm{~ms}^{-1}\right)$ compared to the other direction $\left(12 \mathrm{~ms}^{-1}\right)$. The synoptic situation responsible for the splitting of the wind direction has been deduced from the NCEP reanalysis field. The climatological mean of MSLP was calculated from 1979 to 2005 from NCEP reanalysis data. Then, the average MSLP from all cases of SWEs from northeasterly and southwesterly directions during the climatological base period was calculated separately. Anomalies were obtained by subtracting the averages of these added SWE cases from the climatological MSLP. The area considered was from $90-65^{\circ} \mathrm{S}$. Figures 5 (a) and 5 (b) show the average MSLP anomaly for all SWEs from the directions 45 to $90^{\circ}$ and 135 to $180^{\circ}$ respectively. The predominant feature of these figures is the presence of negative pressure anomalies, which correspond to a low pressure system in the vicinity of the Ross Ice Shelf. The average MSLP anomalies for all SWEs with a northeasterly direction show a weak positive pressure anomaly positioned on the Ross Ice Shelf / Ross Sea and negative pressure anomaly on the north of Ross Sea (Figure 5 (a)). For winds from $135-180^{\circ}$, the MSLP field had negative pressure anomalies over the Ross Ice Shelf / Ross Sea (Figure $5(\mathrm{~b})$ ). Though the resultant MSLP pressure in Figures 5 (a) and (b) shows the average of several different synoptic patterns, it shows the summary of MSLP condition associated with the bimodal direction of SWEs. Therefore, the average MSLP pattern associated with the development of SWEs consists of a deeper synoptic low pressure system located nearer to the northern edge of the Ross Ice Shelf. In summary, one of the factors that control bimodal directions of SWEs is the position and strength of the low over the Ross Ice Shelf / Ross Sea.

Figure 1(b) shows a detail map of the AWS locations and topographical features of McMurdo Station. The topography of the region is complex as it consists of Ross 
Island, Black and White Island and Minna Bluff, which influence the surface wind flow over the region. To investigate further the mechanisms behind the bimodal direction, scatter plots of wind speed and wind direction from the years 2003 to 2005 were examined. The scatter plots of wind speed less than $10 \mathrm{~ms}^{-1}$ as well as for all wind events prevail in all directions. Figure 6 shows a scattered diagram of all McMurdo SWEs from 2003-2005. It is evident that when the speed is greater than $15 \mathrm{~ms}^{-1}$, the SWEs were mainly from the south and with a few events with speed ranging from 11 to $15 \mathrm{~ms}^{-1}$ from the northeast. This may be explained by the fact that when the wind speed is less than $15 \mathrm{~ms}^{-1}$, the prevailing southerly wind flows around the topographic barriers of Minna Bluff and Black and White Island. The flow that passes to the east of Black and White Island is deflected into a north easterly as it encounters Ross Island (Sinclair, 1988, Seefeldt et al., 2003). Here, two cases were chosen to illustrate and understand the surface wind flow around Ross Island in relation to the bimodal direction of SWEs. The first case represents the low wind speed regime when the speed at Williams Field AWS was less than $15 \mathrm{~ms}^{-1}$. Even though it is difficult to generalise, all the SWEs using two cases, the selected case studies illustrate more feature to be the representatives of two categories. Figure 7(a) shows streamlines at 2300 UTC 10 October 2003 from the $3.3 \mathrm{~km}$ grid of AMPS output when the wind speed at Williams Field AWS was less than $15 \mathrm{~ms}^{-1}$. When the speed is greater than $15 \mathrm{~ms}^{-1}$, the southerly flow will have enough energy to override the topographical features and on such occasions McMurdo Station experiences a southerly flow. This is illustrated in the Figure 7(b). A comparison of the surface wind directions from the AMPS data with that from the AWS data carried out by Parish et al. (2006) showed that there was only a minor deviation from the observed wind directions. However, AMPS cannot fully 
resolve the high resolution features of the topography and its impact on the surface winds. For example, the Mt. Erebus (on Ross Island) was resolved by the 3.3-km grid with a height of $2700 \mathrm{~m}$ instead of $3794 \mathrm{~m}$. Similarly, the heights of Black and White Island were also underestimated in the AMPS. Therefore, in actual situations, there will be fewer streamlines across the topography during the low wind condition attributable to greater blocking effect produced by these topographical features.

Here, the Froude number is used (Fr) to examine the relationship between wind speed, stability and flow around the topographical features. When $\operatorname{Fr}>1$ the air flow will have sufficient kinetic energy to traverse the topography, but if $\mathrm{Fr}<1$ this will not occur. Instead, flow will be forced around the topographical feature. The Froude number can be represented as

$$
F r=U\left(\frac{\Delta \theta}{\theta} g h\right)^{-1 / 2}
$$

where $\mathrm{U}$ is the wind speed, $\mathrm{h}$ is the height of the topographical feature, $\Delta \theta$ is the difference in potential temperature between the surface and the top of topographical feature, and $\theta$ is the average potential temperature of the layer between the surface and the height of the topographical feature. Here we used $\mathrm{h}=1000 \mathrm{~m}$ as an average height of both Minna Bluff and Black and White Island and the wind speed was taken as $15 \mathrm{~ms}^{-1}$.

Figure 8 gives the Fr number during January, April, July and October, which were selected to represent the summer, autumn, winter and spring periods respectively. Twice daily radiosonde data from McMurdo Station were used to calculate the Fr number. From the figures, it is evident that the numbers of events with Fr greater than 1 are more common during the summer than during other seasons, which indicates 
possibility of more occasions of flow to override the topography and more southerly SWEs. It is apparent that during summer when the atmosphere is comparatively unstable, less energy is required to override the topographical barrier, therefore more possibility of southerly SWEs occur. This shows that the atmospheric stability is also a factor that controls seasonality in the bimodal direction of SWEs.

To confirm the effects of topography on the wind direction over this area, data from AWSs near Ross Island was analysed. AWS Laurie II $\left(77.50^{\circ} \mathrm{S} 170.79^{\circ} \mathrm{E}\right)$ is located to the east of the island and AWS Ferrell $\left(77.83^{\circ} \mathrm{S} 170.83^{\circ} \mathrm{E}\right)$ to the south east away from influences of the complex topography of the northwest Ross Ice Shelf (see Figure 1(b)). Figure 9 (a) shows a scatter plot of AWS Laurie II 10 minute mean wind directions when the wind speed exceeds Beaufort scale 6 in the year 2003. The wind directions here are primarily confined to $180^{\circ}$ to $270^{\circ}$ and the bimodal distribution of wind directions is absent at the station. Similarly, wind observations at AWS Ferrell show the prevalence of south to southwesterly with no bimodal distribution in the directions (Figure 9 (b)). It is evident that in the absence of the topographical features south of McMurdo Station the bimodal direction is not observed. This shows that topography, the mean position, strength of the low pressure systems in the vicinity of the Ross Ice Shelf as well as the stability of the atmosphere play an important part in controlling the bimodal direction.

\section{3 (d) The Synoptic Environments giving SWEs on the Ross Ice Shelf}

The number of SWEs at the coastal station in Antarctica are influenced by the cyclone density as well as the locations on the coast where storms passing from west to east over the Southern Ocean. However, McMurdo Station is away from the main storm track 
because of its southerly location (Turner et al., 2009). The synoptic situation under which the SWEs at McMurdo Station develop has been analysed using the MSLP and the temperature anomalies. Figure 10 (a) shows a scatter plot of MSLP anomalies with wind speed for SWEs. Analysis of the frequency distribution of MSLP anomalies with the SWEs shows that about $63 \%$ of SWEs are associated with a positive MSLP anomaly greater than $10 \mathrm{hPa}$ and $37 \%$ of SWEs are associated with a negative MSLP pressure of less than $10 \mathrm{hPa}$. This resulted in a fan-shaped distribution with SWEs of highest wind speed associated with large negative pressure anomaly, which can be interpreted as the passage of low pressure systems. Some of the SWEs are also associated with positive MSLP anomalies, which show ridges developing from the interior or the involvement of air coming down from the Antarctic plateau.

Figure 10 (b) illustrates the relationship between the temperature anomaly and wind speed, which shows the majority of SWEs are associated with large positive temperature anomalies. This shows the involvement of warmer air associated with the disruption of the inversion due to the strong winds or re-circulated maritime air. The case of SWEs with negative anomalies is generally associated with the strengthening of high pressure developing over the interior bringing very cold air to the coast. In this case there is little involvement of maritime air masses and despite breaking down the inversion, it results in negative temperature anomalies. However, the number of such cases here is less than those associated with positive temperature anomalies. In summary, many of the SWEs over the McMurdo Station area are associated with positive temperature anomalies and negative pressure anomalies showing that SWEs are associated with depressions that penetrated onto the Ross Ice Shelf.

A typical example of a SWE with a negative MSLP pressure anomaly of 
- $22.5 \mathrm{hPa}$ noted during the period of study is shown in Figure 11(a). This figure illustrates the MSLP from the NCEP reanalysis field at 1200 UTC 15 May 2004 and in this particular case the temperature anomaly was $+7.3^{\circ} \mathrm{C}$ with a wind speed of $17 \mathrm{~ms}^{-1}$. The maximum southerly wind of $38 \mathrm{~ms}^{-1}$ was reported at McMurdo Station during this event. Detailed analysis of this event involved in producing the severe winds at McMurdo are given by Powers (2007) and Steinhoff et al. (2008). The minimum MSLP observed at the station during this event was $947 \mathrm{hPa}$. Here the low tracked from the Amundsen Sea to Marie Bird Land and the Siple Coast (See Figure 1(a) to refer the locations) and then on to the Ross Ice Shelf, before moving westwards towards the station bringing in the warm maritime air. This case illustrates that SWEs at McMurdo Station are linked with synoptic scale systems that have penetrated into the Ross Ice Shelf and enhanced the southerly flow.

Figure 11(b) shows the MSLP chart from the NCEP reanalysis at 0600 UTC 26 May 1982 when a SWE was associated with positive pressure anomaly. For this event the pressure anomaly at McMurdo Station was $+10.2 \mathrm{hPa}$ with a MSLP of $1002.9 \mathrm{hPa}$ and a temperature anomaly of $-4.2^{\circ} \mathrm{C}$. The negative temperature anomaly indicates the involvement of cold, plateau air. As with any other coastal station in Antarctica, conditions over the interior can have a significant effect on the development of SWEs. The synoptic environment associated with the large positive pressure anomalies shows high pressure developing from the interior of the continent towards the coast. The mechanism responsible for the development of this particular SWE was the generation of a pressure gradient induced by the ridge developing from the continental interior and a trough extending from the north of Ross Ice Shelf in the circumpolar trough (CPT). There was a weak trough over the Ross Sea. The combined effects of the 
trough and continental high building from the interior towards the coast increased the existing gradient over the Ross Ice Shelf and the interior continent into stronger pressure gradient, which in turn caused a strong surge of north easterlies with a wind speed of $15.8 \mathrm{~ms}^{-1}$.

\section{INTERANNUAL VARIABILITY IN THE NUMBER OF SWES}

Many meteorological parameters measured at the Antarctic stations have a high interannual variability, and this is also the case with the number of SWEs. Figure 12 shows the number of SWEs of Beaufort scale 6 and above in winter at McMurdo Station from 1979 to 2005 . It is evident from the figure that the inter-annual variability is large and varies from less than 10 events in 1994 to 42 in 1984. The number of SWEs in any one winter at the station can vary due to a number of factors, such as the number and depth of depressions over the Ross Ice Shelf and the Ross Sea. These variations could be a result of natural variability in the number of depressions in this area. However, the region is also on the periphery of the 'polar of variability' in storm activity, which has been attributed to the off-pole nature of the Antarctic continent (Lachlan-cope et al., 2001).

The MSLP anomaly pattern for years of many events (not shown) consists of a negative anomaly over the Ross Ice Shelf, Amundsen Sea and Adélie Land and a larger positive MSLP anomaly over the Bellingshausen Sea area (See Figure1(a) to refer the locations). The anomaly pattern in years of few SWEs shows a small positive pressure anomaly over the Ross Ice Shelf. A number of previous studies (Carleton and Fitch, 1993; Simmonds et al., 2003, Hoskins and Hodges, 2005) have indicated a high frequency of cyclogenesis along the Antarctic coast near $150^{\circ} \mathrm{E}$. The studies have also 
shown that these low pressure systems generally take an eastward track and spiral southeastward into the Ross Sea and coastal Marie Byrd Land (Bromwich et al, 2011). It is also possible for the eastward propagating low pressure systems to recurve and be forced to penetrate into the north of the Ross Ice Shelf depending on the position of the positive pressure anomaly or the high pressure ridge over the Bellingshausen Sea region. This suggests that the synoptic condition over the area around $150^{\circ} \mathrm{E}$ can influence the number of winter SWEs at McMurdo Station. In addition, the strength and the position of Amundsen Sea Low (ASL) and the presence high pressure ridge over the Bellingshausen Sea also influence SWEs numbers. To investigate the effect of upper level factors in controlling the interannual variability, the geopotential height anomaly for years with many and few SWEs were analysed. Figure 13 presents the average winter $500 \mathrm{hPa}$ height anomaly for the year 1984, which had many (42) SWEs. The prominent feature for years with many events is a negative geopotential height anomaly over the Ross Ice Shelf/Ross Sea and a positive anomaly over the Antarctic Peninsula region. For the years 1994, 1997, 1998 when few events were reported, the $500 \mathrm{hPa}$ geopotential height anomaly shows a low negative anomaly over the Ross Ice Shelf with positive anomaly over the continent on the eastern side of the Ross Ice Shelf. The synoptic activity in the area has also been linked to changes in the major modes of climate variability, such as the ENSO and SAM and the role of these in modulating the number of SWEs will be considered in the following sections. 


\section{LINKS BETWEEN THE NUMBER OF SWES AND THE MAJOR MODES OF CLIMATE VARIABILITY}

Previous studies showed that in the Ross Sea area there are some indications of consistent changes in atmospheric circulation at different stages of the ENSO cycle (Cullather et al., 1996; Bertler et al., 2004). This part of the study attempts to determine if ENSO affects the number of SWEs and examines the mechanisms that could control such a relationship.

Table 2 lists the El Niño and La Niña winters based on the 3 month running mean SST anomaly in the Niño 3.4 region obtained from the Climate Prediction Center of NCEP. (http://www.cpc.ncep.noaa.gov/products/analysis_monitoring/ensostuff/

ensoyears.shtml.) For this study, a year was selected as being in the El Niño phase if at least 3 winter months had a running mean SST anomaly that was positive and greater than 0.5 and La Niña if it was less than -0.5. Here only winter months are considered in order to obtain the link between ENSO and inter-annual variability of winter SWEs since the variability in the number of SWEs is large during winter.

In Figure 12, the markers represent the El Niño (triangle marker) and La Niña years (star marker). The figure shows that all the El Niño years coincide with years of fewer SWEs except for 1987 and 2004. The mean numbers of SWEs during El Niño years and La Niña years from 1979 to 2005 are 14 and 21 respectively. This indicates that on average there is less storm activity in the McMurdo Station region during El Niño events than non El Niño periods. 
The mean MSLP anomaly was derived from the NCEP reanalysis data for all El Niño years from 1979 to 2005 (not shown). This had a positive pressure anomaly near the Antarctic Peninsula and over the Bellingshausen Sea with a weaker positive MSLP anomaly over the Ross Ice Shelf. A weak negative pressure anomaly was also apparent over the northern Ross Sea. This pattern of positive and negative anomalies is part of the Rossby wave train from the tropical Pacific that is present during El Niño events, and which extends towards the Antarctic Peninsula in a southeasterly direction (Turner, 2004). The mean MSLP data for winter shows that the ASL occupies a location near the eastern edge of the Ross Ice Shelf, extending farther east and closer to the Antarctic Peninsula. This climatological feature is associated with more cyclonic activity in this region. The average MSLP anomalies for the four La Niña cases during the period between 1979-2005 (not shown) had a negative pressure anomaly (deeper ASL) extending longitudinally from Marie Byrd Land to the Bellingshausen Sea (See Figure 1(a) to refer the locations). A small negative pressure anomaly was present over the Ross Ice Shelf. This would suggest a larger number of depressions or more intense systems across the region, which demonstrates ENSO modulating the interannual variability of SWEs. However, when MSLP anomalies during individual El Niño years were analysed, the patterns shows a rather anomalous signature over the Antarctic in some years with a weak negative pressure anomaly over the Bellingshausen Sea. Similar anomalous patterns were evident for some La Nina years. Examining the MSLP anomalies during several years of El Niño and La Niña, it is evident that even though the Ross Sea region is sensitive to the impact of ENSO on MSLP, the signal is not consistent. It should also be noted that the MSLP anomaly patterns for more or fewer SWEs at the station do not have their largest signatures in the area of the Ross Sea/Ross 
Ice Shelf, but are found to the west of the Peninsula over the Amundsen-Bellingshausen Seas. This suggests that the number of SWEs is also modulated by regional MSLP anomalies and not just the pressures in the immediate vicinity of the station. The strong similarity of the patterns with the anomalies associated with El Niño and La Nino events implies that tropical climate variability plays a part in dictating the number of SWEs, though there is only a weak long term relationship. The dependence of decadal variability and seasonality of SWEs with the Southern Oscillation Index (SOI) index was also investigated, considering the correlation of the number of SWEs with the SOI in a shorter period between 1980 to 1990 and 1990 to 2000 over the austral summer, spring and autumn. The analysis failed to capture any statistically significant relationship.

In summary, there is some indication of the role of ENSO in modulating the number of SWEs in the Ross sea region but the lack of consistency in the response indicates the possibility of a non-linear relationship. In addition, it is difficult to make any robust conclusions based on the short record that is available.

\section{THE RELATIONSHIP BETWEEN THE INTER-ANNUAL VARIABILITY IN THE NUMBER OF SWES AND THE SAM}

Climate variability in the high-latitude Southern Hemisphere is dominated by the southern annular mode, a large-scale pattern of variability which is also referred to as High-Latitude Mode.Thompson and Solomon (2002) showed that the greatest increases in the SAM were in the austral summer and autumn (December-May). The variability in SWEs are greatest during autumn compared to summer. Therefore, to investigate the relationship between the variability of SWEs and SAM, the SAM index from Marshall 
(2003) for 1979 to 2005 autumn was used. Figure 14 presents the autumn SAM index from 1979 to 2005 and the number of autumn SWEs. Prior to 1990 the number of SWEs was not correlated with the SAM index. From 1990 to 2000 the SAM and inter-annual variability of SWEs are in the same phase with a correlation coefficient of $0.6(<5 \%$ significant). The relationship again changed over 2000 to 2005 to a weak correlation of 0.33. The numerical definition employed to define the SAM is the difference between the normalised monthly zonal MSLP at $40^{\circ} \mathrm{S}$ and $65^{\circ} \mathrm{S}$. The negative phase of SAM implies lower MSLP at $65^{\circ} \mathrm{S}$ and more SWEs. This explains only a small portion of the inter-annual variability in the number of SWEs and there can be a lot of other factors influencing the phase changes that must be invoked in order to understand the variability fully. In addition, there is an in-phase relationship between SOI index and SAM from 1990 to 2000 (Fogt and Bromwich, 2006). This shows that to get a significant positive correlation between the SAM and interannual variability of SWEs both tropics and the high latitude variability need to be in phase. There was no statistically significant relationship observed between the SAM and interannual variability in the number of SWEs during the other seasons.

\section{THE TREND IN THE MEAN WIND SPEED AND THE NUMBER OF SWEs}

A major problem in determining the trend in the number of SWEs is the relatively short in-situ record that is available and the incomplete nature of the wind records during the winter months from the stations, which have large gaps.

An examination of the trends in the mean monthly wind speed at McMurdo Station shows (Figure 15) that there has been a decrease throughout the year with a 
major drop in March. The long term mean (1979-2005) MSLP for March shows (Figure 16) that McMurdo Station (marked by black dot in the Figure 16) is south of the average position of the circumpolar trough. Therefore, the broad scale wind speed is controlled by the gradient between the low centre over the Amundsen/Ross Sea and the average pressure over the interior. The long term trend (1979-2005) in MSLP for March shows that there are a number of areas around the coast of East Antarctica where the trend in MSLP is positive (Figure 17). There are large positive trends in pressure over the Ross Ice Shelf and the coastal area. This has resulted in a weaker pressure gradient across the station, which is reflected in the decreasing trend in the wind speed.

The Figure 18 shows the number of winter SWEs at McMurdo Station from 1979-2005. A small negative trend is observed (-0.25) which is not significant. The long term trend in mean winter MSLP pattern is similar to the pattern in March (see Figure 17) with a large positive pressure trend over the Ross Ice Shelf, which is in agreement with the decrease in the number of SWEs at McMurdo Station (see Figure 18).

\section{DISCUSSION AND CONCLUSIONS}

In this paper the SWEs at McMurdo Station on the northwest Ross Ice Shelf were considered using the available in-situ data and reanalysis fields. The definition of a SWE in this study was taken as a 10 minute mean surface wind speed of greater than Beaufort Scale $6(22$ knots or $11.3 \mathrm{~m} / \mathrm{s})$. The annual cycle in the number of SWEs shows a semi-annual oscillation. The SWEs at McMurdo Station exhibits a bimodal distribution in direction, which is more pronounced during the winter. On the Ross Ice Shelf the prevailing wind direction is southerly and when the wind flow lacks the energy to override the topography it flows around Minna Bluff and Black and White 
Island. When it approaches Ross Island it splits in to easterly and westerly streams around the island. Therefore, during such a flow, McMurdo Station experienced SWEs from a northeasterly direction. If the southerly flow is strong enough to override the topographic features south of McMurdo Station, the station experiences southerly SWEs. The bimodal distribution in the direction of SWEs was also found to be associated with the location and strength of low pressure system north of the Ross Ice Shelf as well as wind speed and atmospheric stability. At McMurdo Station the strongest winds were mostly a result of the deep depressions that penetrated into the Ross Ice Shelf and were associated with large negative pressure anomaly and positive temperature anomaly. Some SWEs occurred when there was a large positive pressure anomaly and negative temperature anomaly as a ridge of high pressure from the interior enhances the pressure gradient between the continent and low offshore.

The inter-annual variability in the number of SWEs at McMurdo Station is large and is associated with a deep trough centred over the northeastern Ross Ice Shelf. The variability is not dependent on the amplitude and location of the atmospheric longwaves around the Antarctic rather it is dependent on the intensification of the trough on the Ross Ice Shelf. The tropical atmospheric and oceanic variability is also linked with variability in the number of SWEs. Although there is no long term stable relationship between the phase of ENSO and number of SWEs, it was shown that fewer SWEs are associated with El Niño events. The correlation between an index of the SAM and interannual variability in the number of SWEs shows a decadal variability and the relationship was found to be stronger when the phase of ENSO and the SAM were the same. 
Since 1979, when reliable atmospheric analyses became available, McMurdo Station observations show a small decrease in the number of SWEs, but the trend is not significant. Although gaps in the McMurdo Station in-situ record can have an effect on the trend in the number of SWEs, the decrease in the number of SWEs is consistent with the positive trend in the gradient of MSLP over the McMurdo Station area.

One of the key features of SWEs at McMurdo Station is the bimodal distribution in the wind direction. SWEs are strongly influenced by the interaction of surface flow with the complex local orography, such as Minna Bluff, Black and White Island. The NCEP reanalysis fields used for the synoptic analysis have a horizontal resolution of $200 \mathrm{~km}$ and cannot resolve Black and White Island although it is known to be important in the wind flow in the area (O'Connor and Bromwich, 1998; Seefeldt et al., 2003). Even though there are two detailed case studies of the May 2004 McMurdo windstorm (Powers ,2007; Steinhoff et al.,2008) it is essential to carry out more in depth case studies of SWEs in this area in order to understand the mechanisms involved in the development of SWEs using higher resolution models.

\section{ACKNOWLEDGEMENTS}

This study was funded by Malaysian Antarctic Research Program, Academy of Sciences, Malaysia. Authors would also like to thank University of Malaya, British Antarctic Survey and Antarctica New Zealand. 


\section{REFERENCES}

Bertler NAN, Barrett PJ, Mayewski PA, Fogt RL, Kreutz KJ, Shulmeiste J. 2004. El Niño suppresses Antarctic warming. Geophysics Research Letters 31: L15207. DOI: 10.1029/2004GL020749.

Birnbaum G, Brauner R, Ries H. 2006. Synoptic situations causing high precipitation rates on the Antarctic plateau: observations from Kohnen Station, Dronning Maud Land. Antarctic Science 18: 279-288.

Breckenridge CJ, Radok U, Stearns CR, Bromwich DH. 1993. Katabatic winds along the Transantarctic Mountains. In Antarctic Meteorology and Climatology: Studies Based on Automatic Weather Stations, Antarctic Research Series, American Geophysical Union, Washington DC. 61: 69-92. Bromwich DH and Stearns CR (eds), DOI: 10.1029/AR061p0069.

Breckenridge CJ. 1985. Foehn events along the Transantarctic Mountians. M.S. thesis, Deptartment of Meteorology, University of Wisconsin-Madison.

Bromwich DH, Carrasco JF, Stearns CR. 1992. Satellite observations of katabatic wind propagation for great distances across the Ross Ice Shelf. Monthly Weather Review 120: 1940-1949.

Bromwich DH, Daniel FS, Simmonds I, Keay K, Fogt RL. 2011. Climatological aspects of cyclogenesis near Adélie Land Antarctica. Tellus 63: 841-1054. DOI: 10.1111/j.1600-0870.2011.00537.

Bromwich DH, Fogt RL, Hodges KI, Walsh JE. 2007. A tropospheric assessment of the ERA-40, NCEP, and JRA-25 global reanalyses in the polar regions. Journal of Geophysical Research 112: D10111, DOI:10.1029/2006JD007859.

Bromwich DH, Kurtz DD. 1984. Katabatic wind forcing of the Terra Nova Bay Polynya. Journal of Geophysical Research 86: 3561-3572.

Bromwich DH, Parish TR, Pellegrini A, Stearns CR, Weidner GA. 1993. Spatial and temporal characteristics of the intense katabatic wind at Terra Nova Bay, Antarctica. Antarctic Meteorology and Climatology: Studies Based on Automatic Weather Stations, Antarctic Research Series, Bromwich DH, Sterns CR, Eds., Antarctic Research Series American Geophysical Union. Washington DC. 61: 47-68.

Bromwich DH. 1989a. Satellite observations of katabatic winds blowing from Marie Byrd Land onto the Ross Ice Shelf. Antarctic Journal of the United States 24: 218-221.

Bromwich DH. 1989b. An Extraordinary Katabatic Wind Regime at Terra Nova Bay, Antarctica. Monthly Weather Review 117: 688-695. 
Bromwich DH. 1991. Mesoscale cyclogenesis over southwestern Ross Sea linked to strong winds. Monthly Weather Review 119: 1736-1752.

Bromwich DH. 1992. A satellite case study of a katabatic surge along the Transantarctic Mountains. International Journal of Remote Sensing 13: 55- 66.

Carleton AM, Fitch M. 1993. Synoptic aspects of Antarctic mesocyclones. Journal of Geophysical Research 98: 12997-13018.

Carrasco JF, Bromwich DH. 1993. Satellite and automatic weather station analyses of katabatic surges across the Ross Ice Shelf. Antarctic Meteorology and Climatology: Studies Based on Automatic Weather Stations, Antarctic Research Series, Bromwich DH, Sterns CR, Eds., American Geophysical Union. Washington 61: 93-108.

Carrasco JF. 1994. Dynamics of mesoscale cyclogenesis adjacent to the Pacific coast of Antarctica. Ph.D. dissertation, The Ohio State University 286 pp.

Cullather RI, Bromwich DH, van Woert ML.1996. Interannual variability in Antarctic precipitation related to El Niño-Southern Oscillation. Journal of Geophysical Research 101: 19109-19118.

Fogt RL, Bromwich DH. 2006. Decadal variability of the ENSO teleconnection to the high-latitude South Pacific governed by coupling with the Southern Annular Mode. Journal of Climate 19: 979-997.

Holmes RE, Stearns CR, Weidner GA, Keller LM. 2000. Utilization of automatic weather station data for forecasting high wind speeds at Pegasus Runway, Antarctica. Weather and Forecasting 15: 137-151.

Hoskins BJ, Hodges KI. 2005. A new perspective on Southern Hemisphere storm tracks. Journal of Climate 18: 4108-4129.

Kalnay E, et al. 1996. The NCEP/NCAR 40-year reanalysis project. Bulletin of the American Meteorological Society, 77: 437-471.

Keable M, Simmonds I, Keay K. 2002. Distribution and temporal variability of $500 \mathrm{hPa}$ cyclone characteristics in the Southern Hemisphere. International Journal of Climatology 22: 131-150.

King JC, Turner J. 1997. Antarctic Meteorology and Climatology. Cambridge University Press, Cambridge.

Kurtz DD, Bromwich DH. 1985. A recurring, atmospherically forced polynya in Terra Nova Bay. Antarctic Research Series 43: 177-201.

Lachlan-Cope T, Ladkin R, Turner J, Davison P. 2001. Observations of cloud and precipitation particles on the Avery Plateau, Antarctic Peninsula. Antarctic Science 13: 339-348. 
Lazzara MA. 2008. A diagnostic study of Antarctic fog. $\mathrm{PhD}$ dissertation, Department of Atmospheric and Oceanic Sciences, University of Wisconsin-Madison.

Marshall GJ. 2003. Trends in the Southern Annular Mode from observations and reanalyses. Journal of Climatology 16: 4134-4143.

Meehl GA. 1991. A re-examination of the mechanism of the semiannual oscillation in the Southern Hemisphere. Journal of Climatology 4:911-925.

Monaghan AJ, Bromwich DH, Powers JG, Manning KW. 2005. The climate of the McMurdo, Antarctica region as represented by one year of forecasts from the Antarctic Mesoscale Prediction System. Journal of Climate 18:1174-1189.

O'Connor WP, Bromwich DH. 1988. Surface airflow around Windless Bight, Ross Island, Antarctica. Quarterly Journal of the Royal Meteorological Society 114: 917938.

Parish TR, Bromwich DH. 1998. A case study of Antarctic katabatic wind interaction with large-scale forcing. Monthly Weather Review 126: 199- 209.

Parish TR, Cassano JJ, Seefeldt MW. 2006. Characteristics of the Ross Ice Shelf air stream as depicted in Antarctic Mesoscale Prediction System simulations. Journal of Geophysical Research 111: D12109, DOI:10.1029/2005JD006185.

Pezza AB, Simmonds I, Filho AJP. 2008. Climate perspective on the large-scale circulation associated with the transition of the first South Atlantic hurricane. International Journal of Climatology 29: 1116-1130. DOI:10.1002/joc17.57.

Powers JG. 2007. Numerical Prediction of an Antarctic Severe Wind Event with the Weather Research and Forecasting (WRF) Model. Monthly Weather Review 135: 31343157. DOI: http://dx.doi.org/10.1175/MWR3459.1.

Seefeldt MW, Cassano JJ. 2008. An analysis of low-level jets in the greater Ross Ice Shelf region based on numerical simulations. Monthly Weather Review 136: 4188-4205, 4188-4205, DOI:10.1175/2008MWR2455.1.

Seefeldt MW, Tripol GJ, Stearns CR. 2003. A high-resolution numerical simulation of the wind flow in the Ross Island Region, Antarctica. Monthly Weather Review 131: 435-458.

Schwerdtfeger W. 1984. Weather and Climate of the Antarctic. Developments in Atmospheric Science, Elsevier Science Publishers 15: 262 pp.

Sinclair MR. 1988. Local topographic influence on low level wind at Scott Base, Antarctica. New Zealand Journal of Geology and Geophysics 31: 237-245.

Simmonds I, Keay K, Lim EP. 2003. Synoptic activity in the seas around Antarctica. Monthly Weather Review 131: 272-288. 
Steinhoff DF, Bromwich DH, Lambertson M, Knuth SL, Lazzara MA. 2008. A dynamical investigation of the May 2004 McMurdo Antarctica severe wind event using AMPS. Monthly Weather Review 136: 7-26.

Turner J, Chenoli SN, Abu Samah A, Marshal G, Phillips T, Orr A. 2009. Strong wind events in the Antarctic. Journal of Geophysical Research 114: D18103, DOI: 10.1029/2008JD011642.

Turner J, Colwell SR, Marshall GJ, Lachlan-Cope TA, Carleton AM, Jones PD et al. 2004. The SCAR READER project: Towards a high-quality database of mean Antarctic meteorological observations. Journal of Climatology 17: 2890-2898.

Turner J. 2004. The El Niño-Southern Oscillation and Antarctica. International Journal of Climatology 24: 1-31.

Van As D, van den Broeke MR, Helsen M. 2007. Strong-wind events and their impact on the near-surface climate at Kohnen Station on the Antarctic Plateau. Antarctic Science 19: 507-519 DOI: 10.1017 /S095410200700065X.

Van Lipzig NP, van Meijgaard ME, Oerlemans J. 2002. The spatial and temporal variability of the surface mass balance in Antarctica: Results from a regional atmospheric climate model. International Journal of Climatology 22: 1197-1217. 


\section{TABLES}

Table 1. Frequency of occurrence of winds in $5 \mathrm{~ms}^{-1}$ bins.

\begin{tabular}{cccccccc}
\hline $\begin{array}{c}\text { Range of wind } \\
\text { speed }\left(\mathrm{ms}^{-1}\right)\end{array}$ & $0-5$ & $06-10$ & $11-15$ & $16-20$ & $21-25$ & $26-30$ & $30<$ \\
\hline $\begin{array}{c}\text { Frequency of } \\
\text { occurrence }(\%)\end{array}$ & 56.30 & 37.05 & 5.99 & 0.51 & 0.10 & 0.02 & 0.03 \\
\hline
\end{tabular}

Table 2. List of El Niño and La Niña winters based on the 3 month running mean SST anomalies between 1979 and 2005.

\begin{tabular}{cc}
\hline El Niño Years & La Niña Years \\
\hline 1982 & 1985 \\
1987 & 1988 \\
1991 & 1998 \\
1992 & 1999 \\
1994 & \\
1997 & \\
2002 & \\
2004 & \\
\hline
\end{tabular}




\section{FIGURE CAPTIONS}

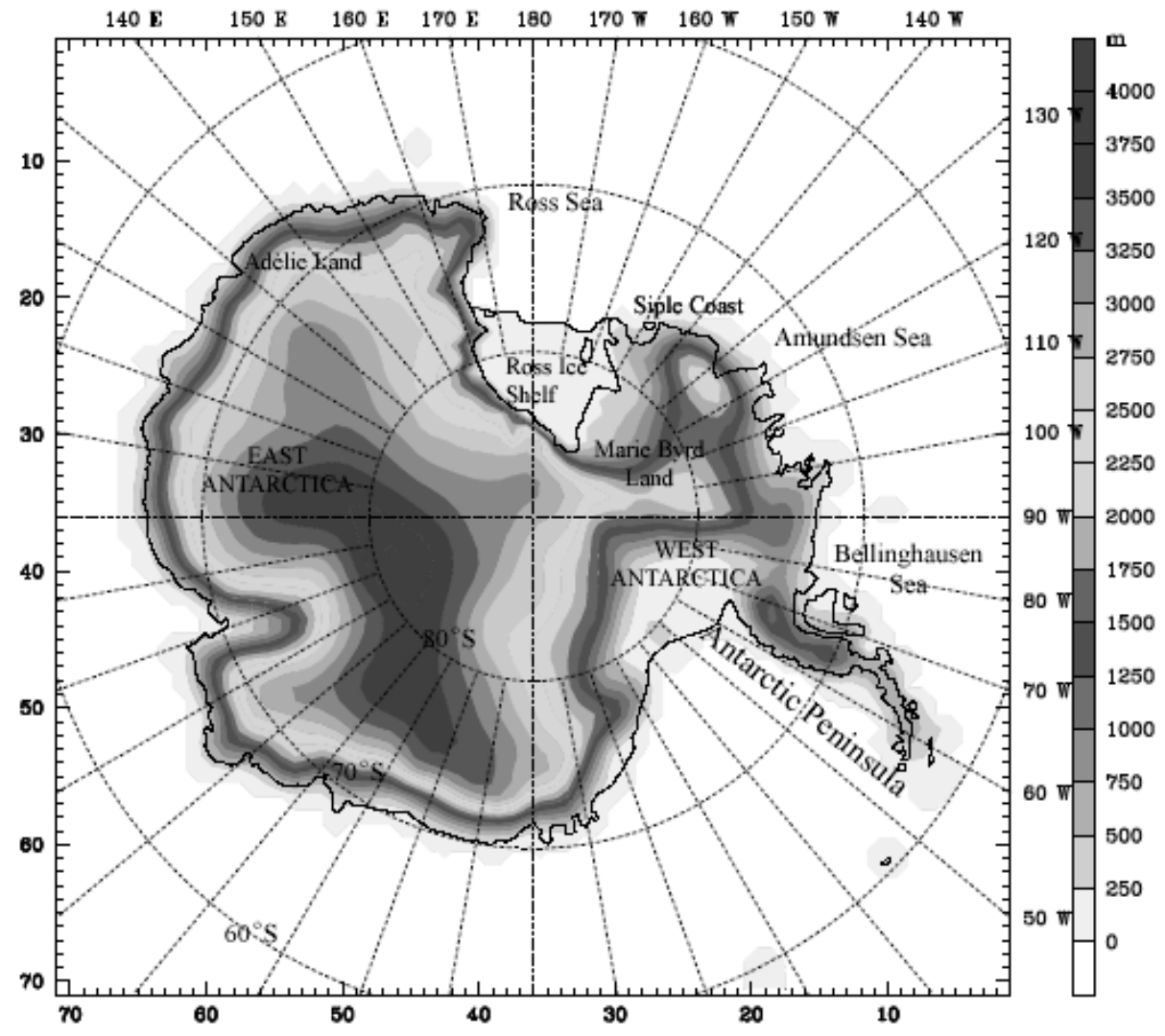

Figure 1(a).A map of Antarctica continent with AMPS terrain contours (shaded, $250 \mathrm{~m}$ interval) showing the locations named in the text. Black dot represents the location of McMurdo Station and the box shows region shown in Figure 1(b) 

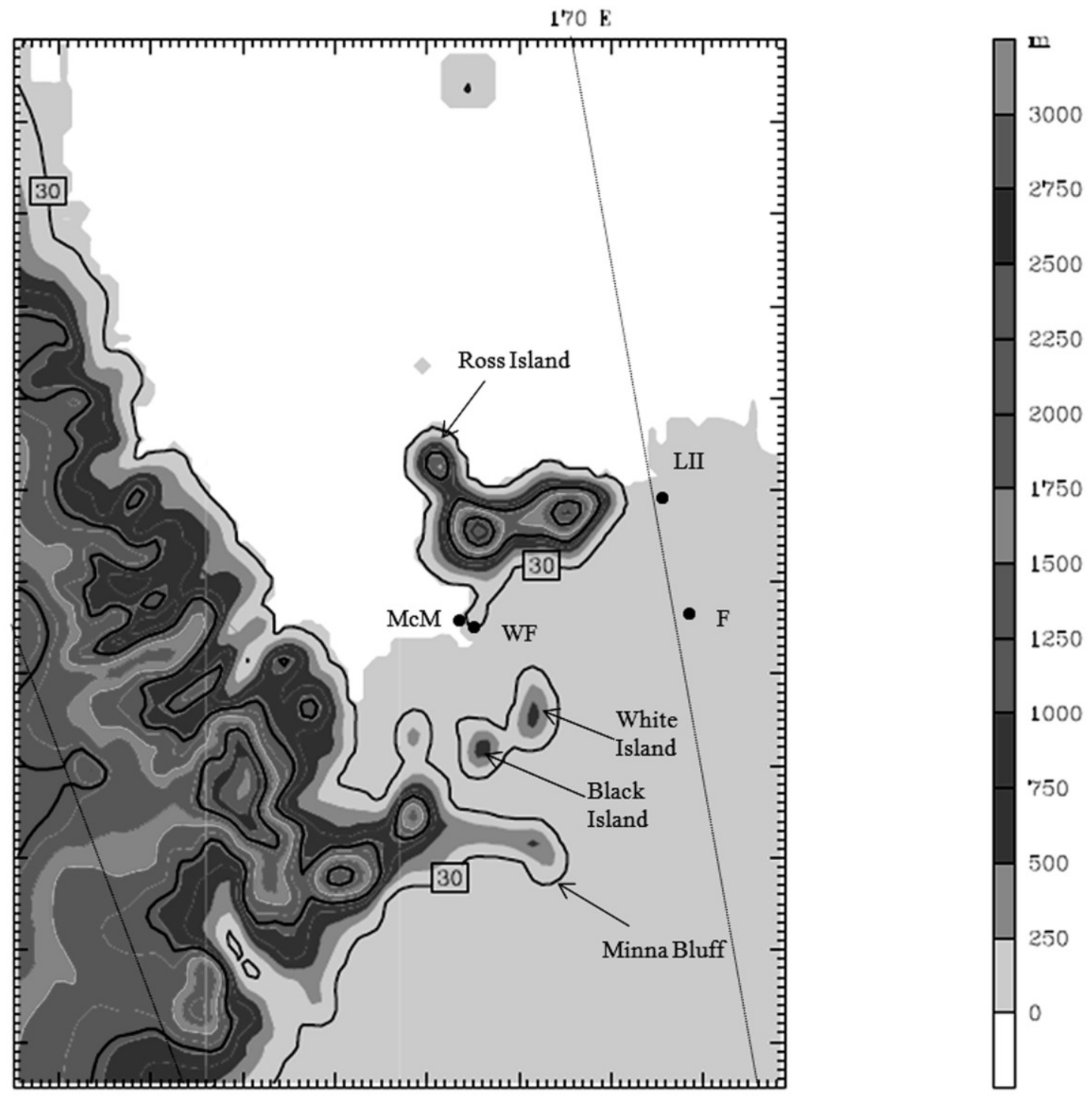

Figure 1(b).A map of the northwest Ross Ice Shelf region with terrain contours from AMPS (shaded, $250 \mathrm{~m}$ interval). McM and WF stand for McMurdo Station and Williams Field respectively. LII and F indicate AWSs Laurie II and Ferrell. 
Annual distribution of number of SWEs from 1979 to 2005

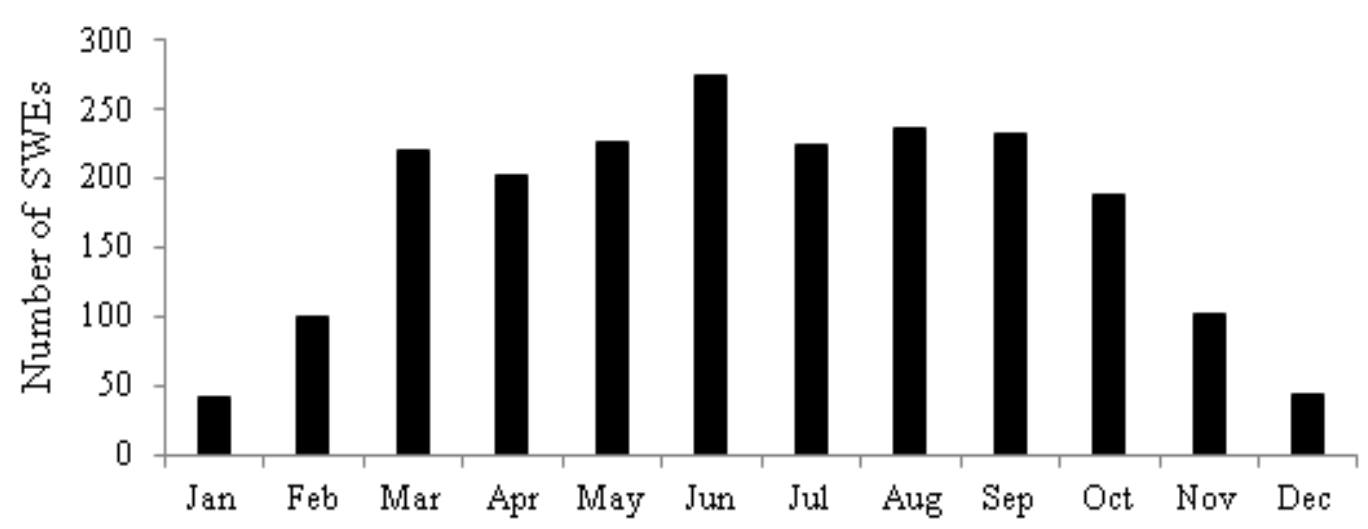

Figure 2.Annual distribution of the number of SWEs for the period $1979-2005$ for McMurdo Station based on a threshold of a single 6-hourly observation with a wind speed greater than Beaufort scale 6 . 


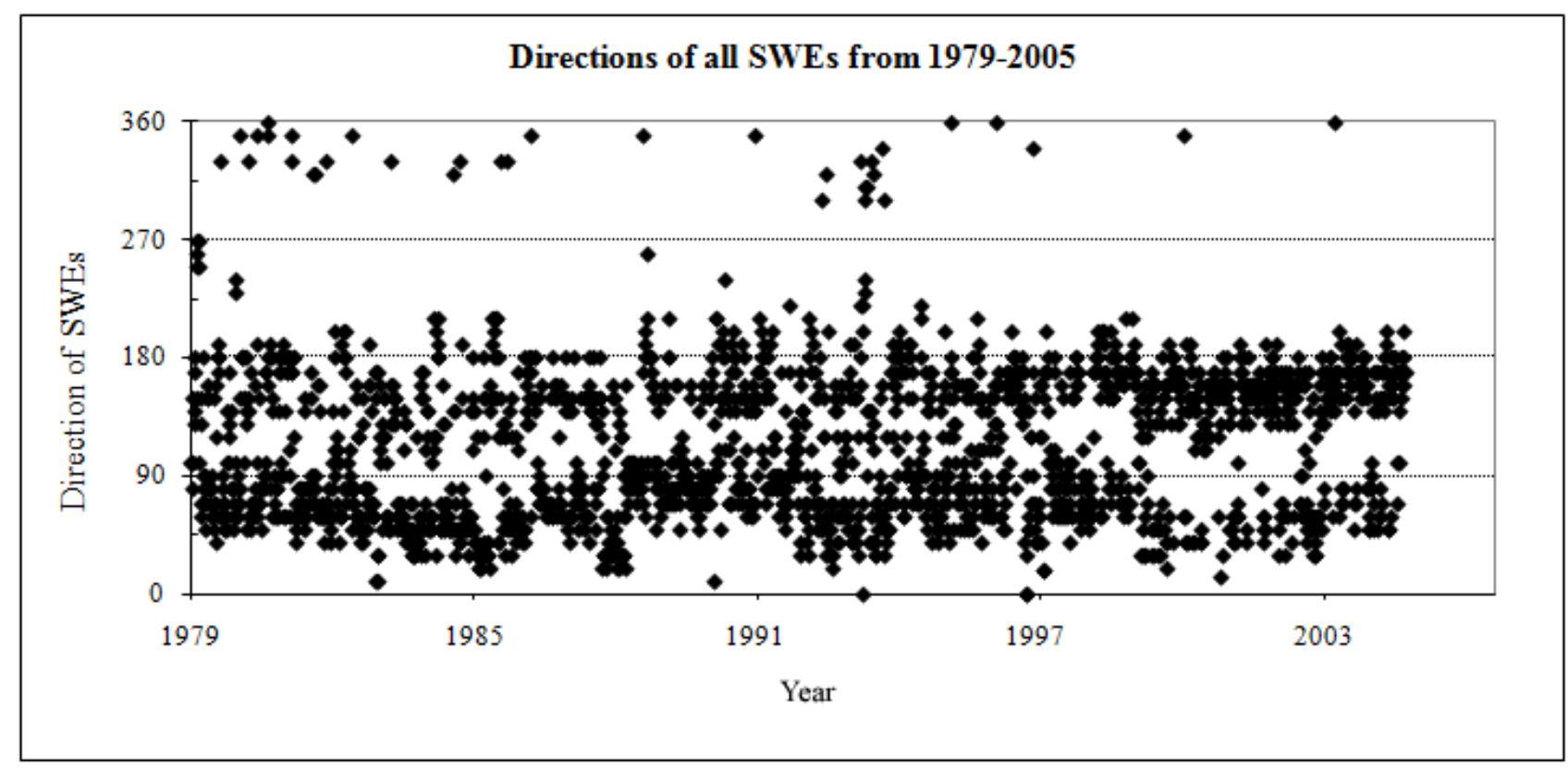

Figure 3.The wind directions of SWEs at McMurdo Station correspond to the SWEs that are indicated in Figure 2. 


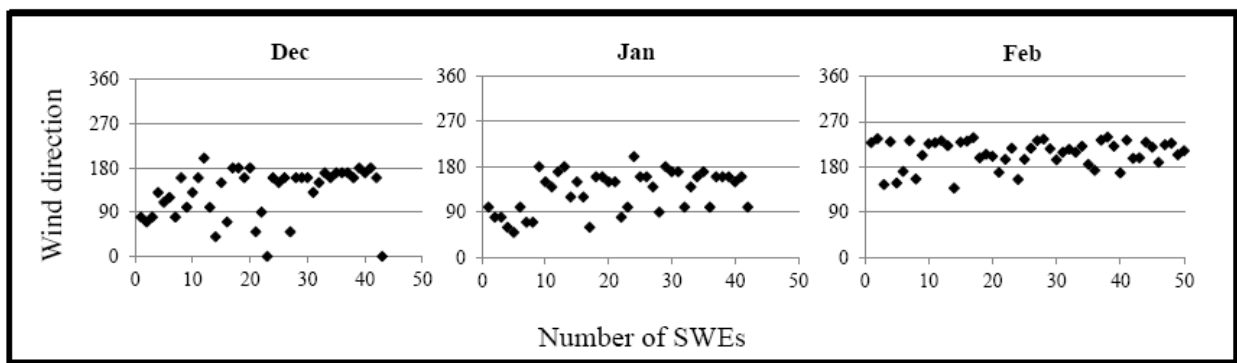

Autumn

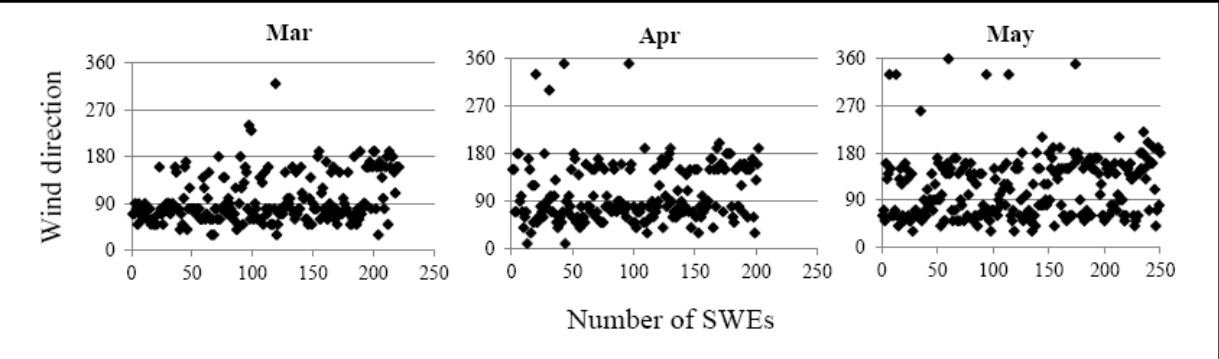

Winter

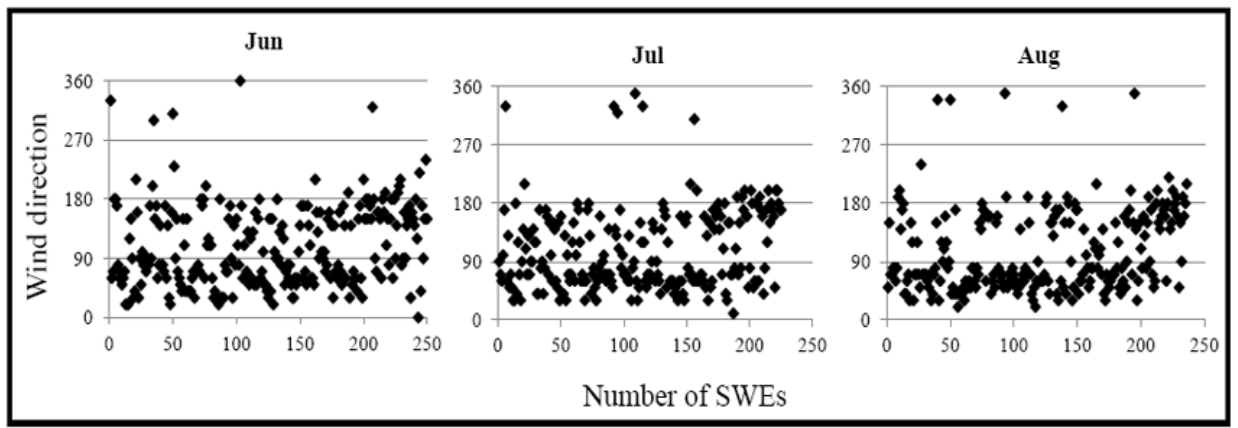

Spring

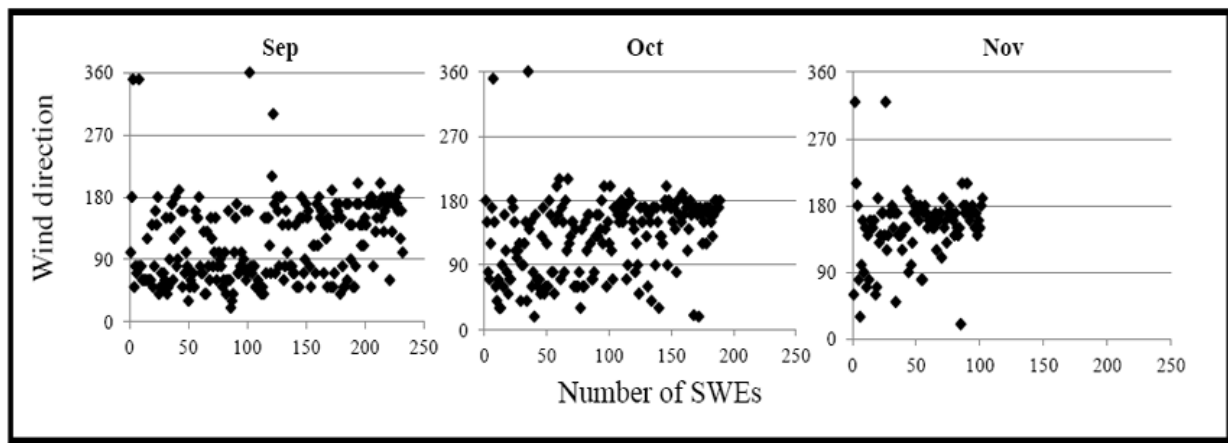

Figure 4.An illustration of seasonal variations in the bimodal distribution of all SWEs during the period of study (wind direction is given on the ordinate and number of events in each month on the abscissa). 


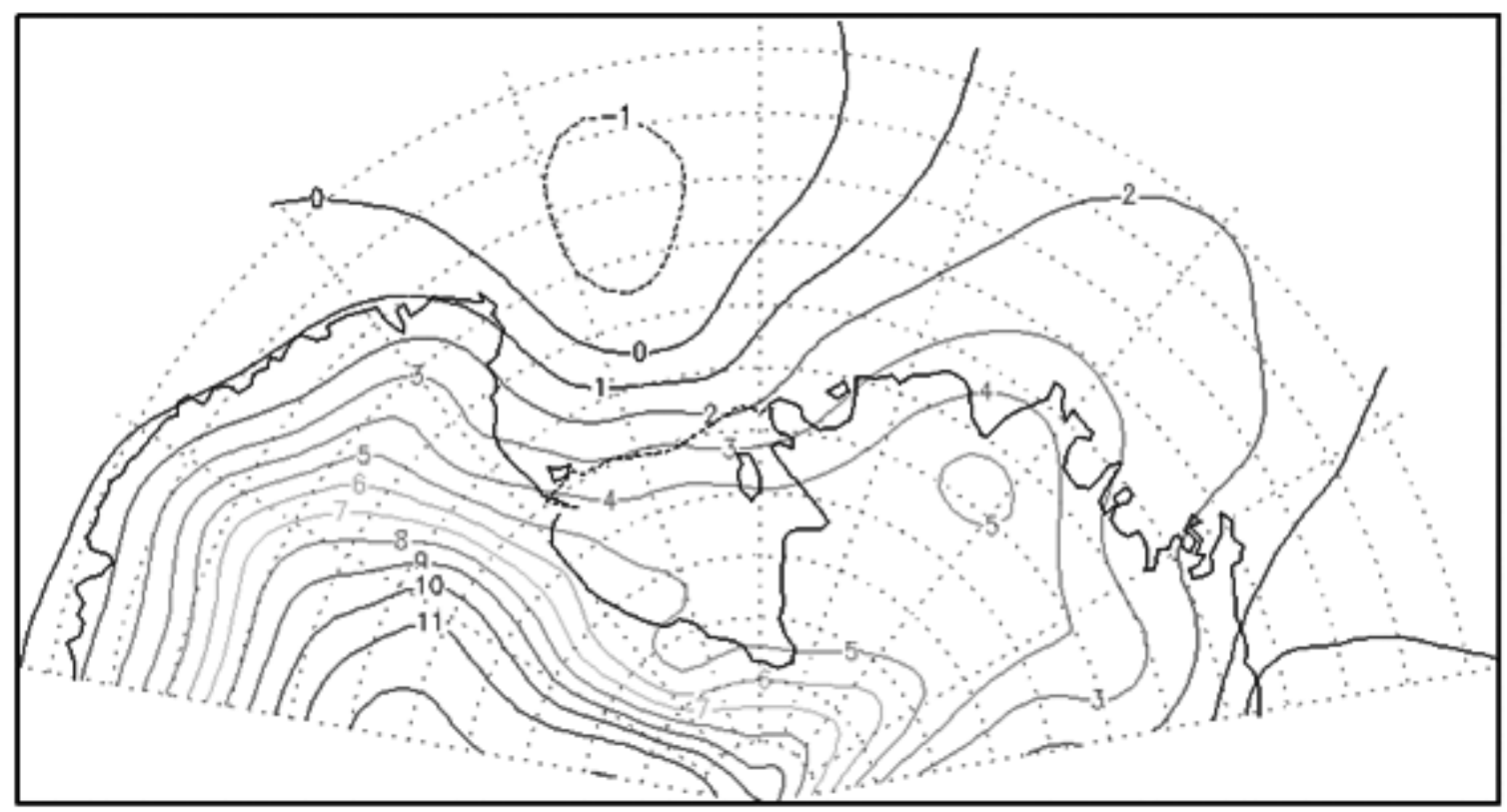

Figure 5(a).MSLP anomaly (hPa) for all SWEs from the directions $45^{\circ}$ to $90^{\circ}$ for the period 1979-2005. The location of McMurdo Station was indicated by the black dot. 


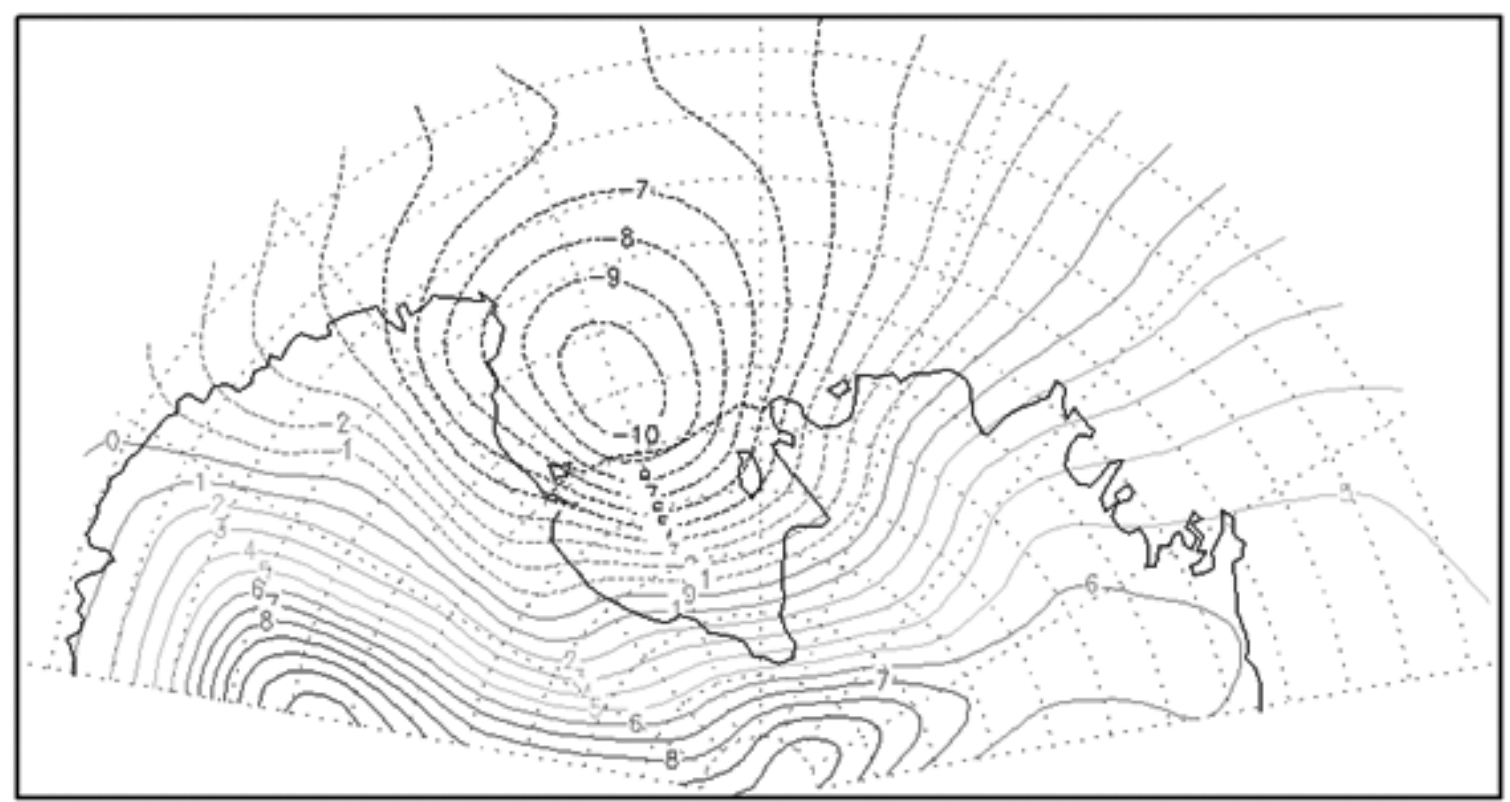

Figure 5(b).MSLP anomaly (hPa) for all SWEs from the directions $135^{\circ}$ to $180^{\circ}$ for the period 1979-2005 with a contour interval of $2 \mathrm{hPa}$. The location of McMurdo Station was indicated by the black dot. 


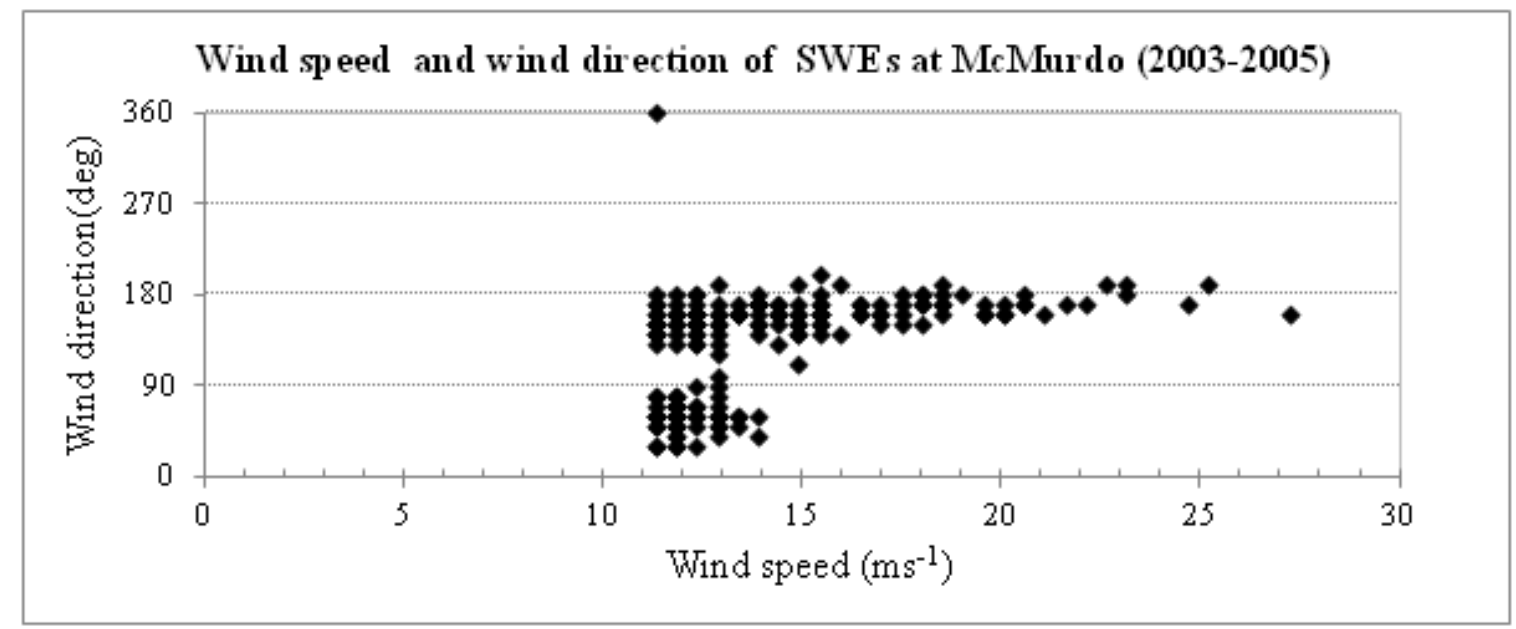

Figure 6. A scatterplot of wind speed $\left(\mathrm{m} \mathrm{s}^{-1}\right)$ against wind direction (in deg) measured at McMurdo Station for the period (2003-2005) when the wind speed was greater than Beaufort scale 6 and above. 

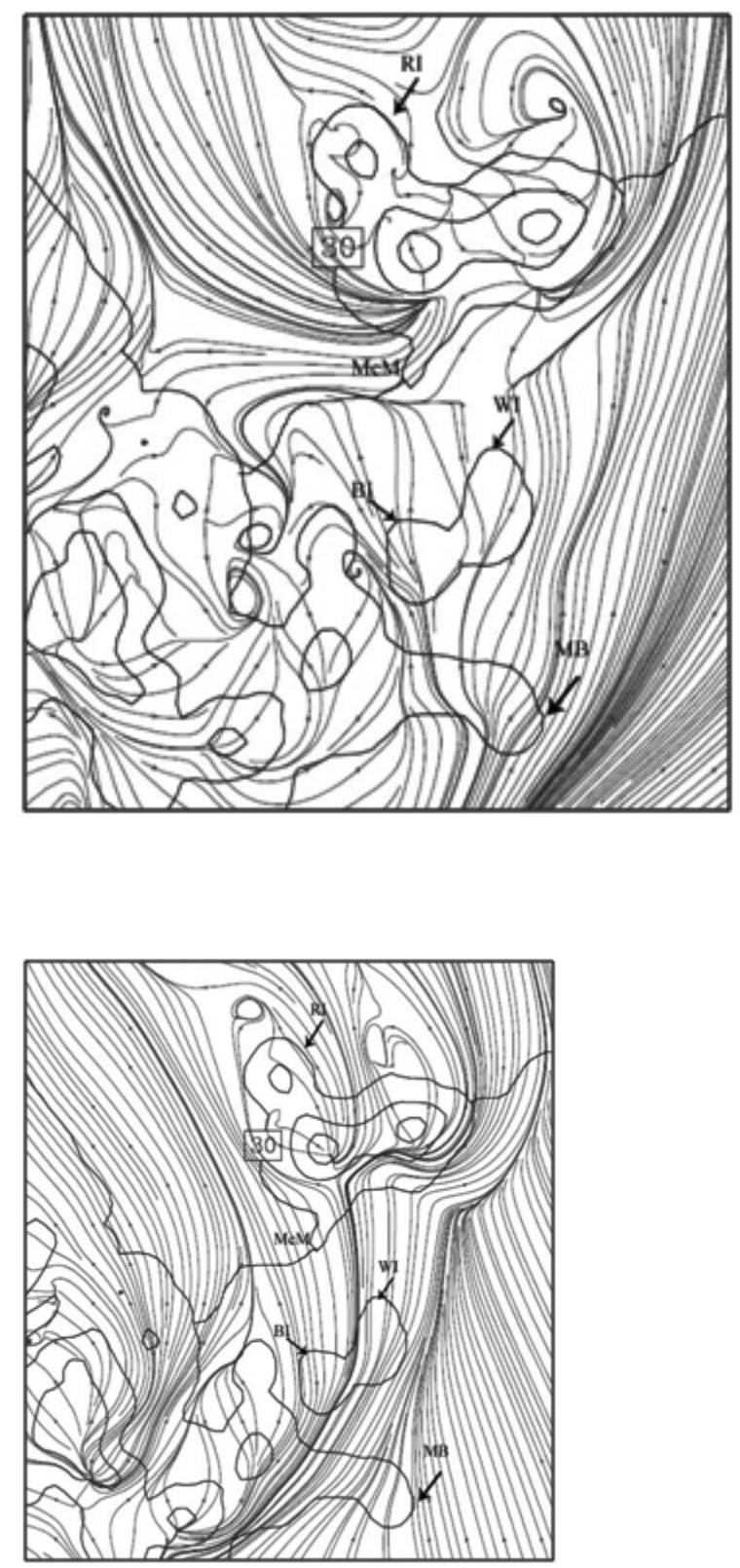

Figure 7. Surface streamlines from the $3.3 \mathrm{~km}$ AMPS grid (a) at 2300 UTC 10 October 2003 and (b) 0400 UTC 16 May 2004. RI, BI, WI and MB denote Ross Island, Black Island, White Island and Minna Bluff respectively. 


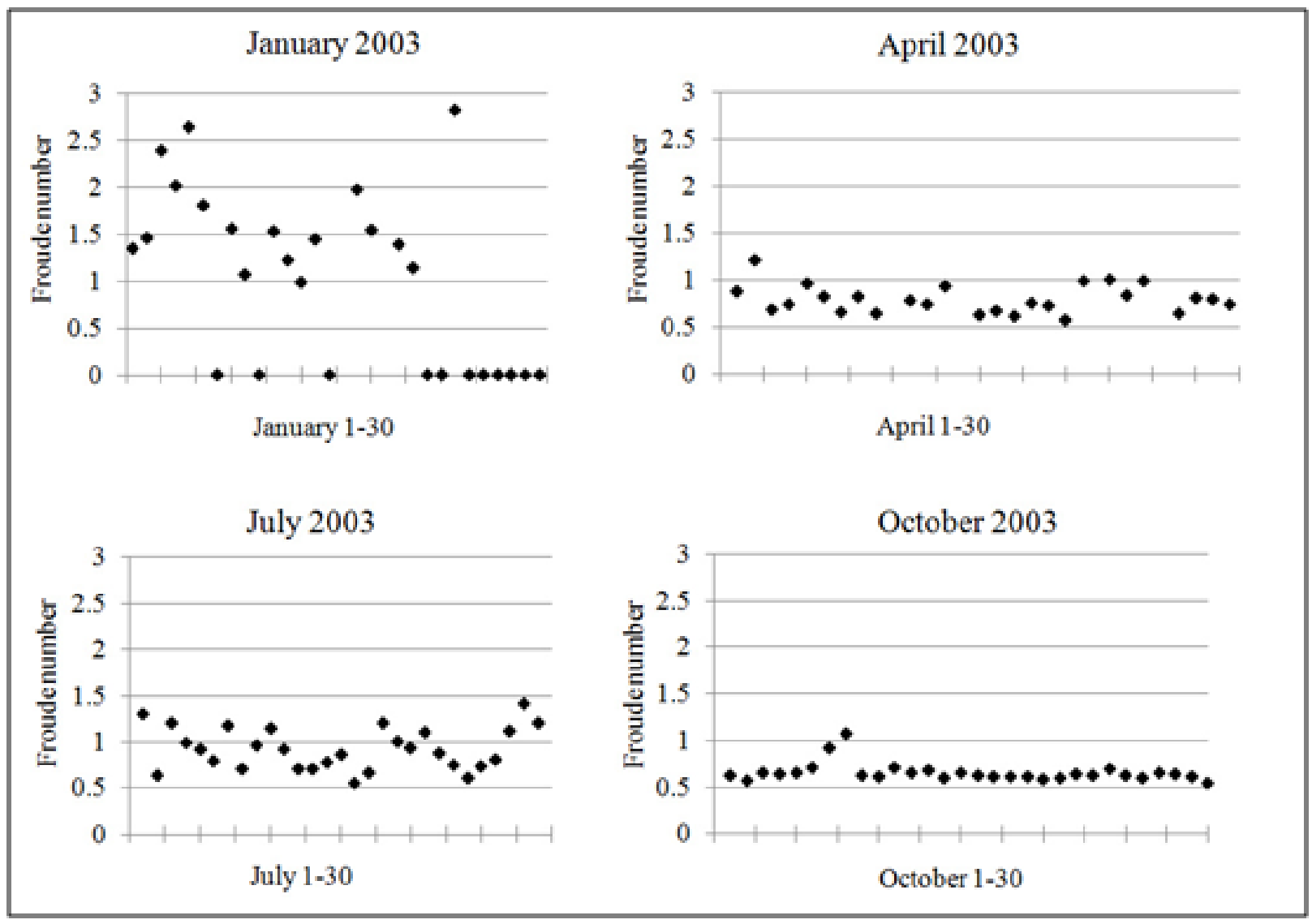

Figure 8.The Froude number calculated for January, April, July and October 2003 using the radiosonde data from McMurdo Station. 


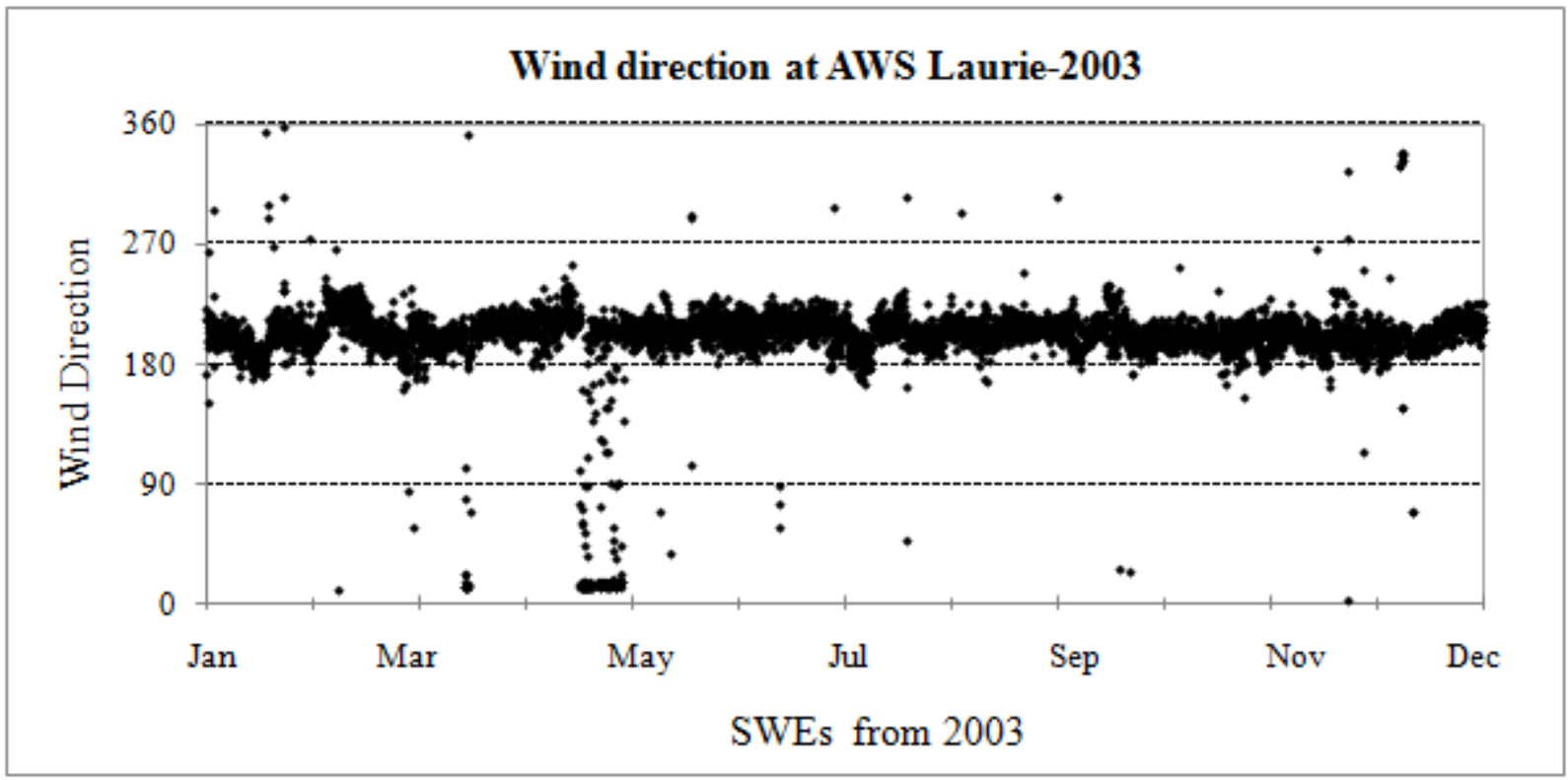

Figure 9(a).The wind direction from AWS Laurie II for the events with wind speed above $10 \mathrm{~ms}^{-1}$.

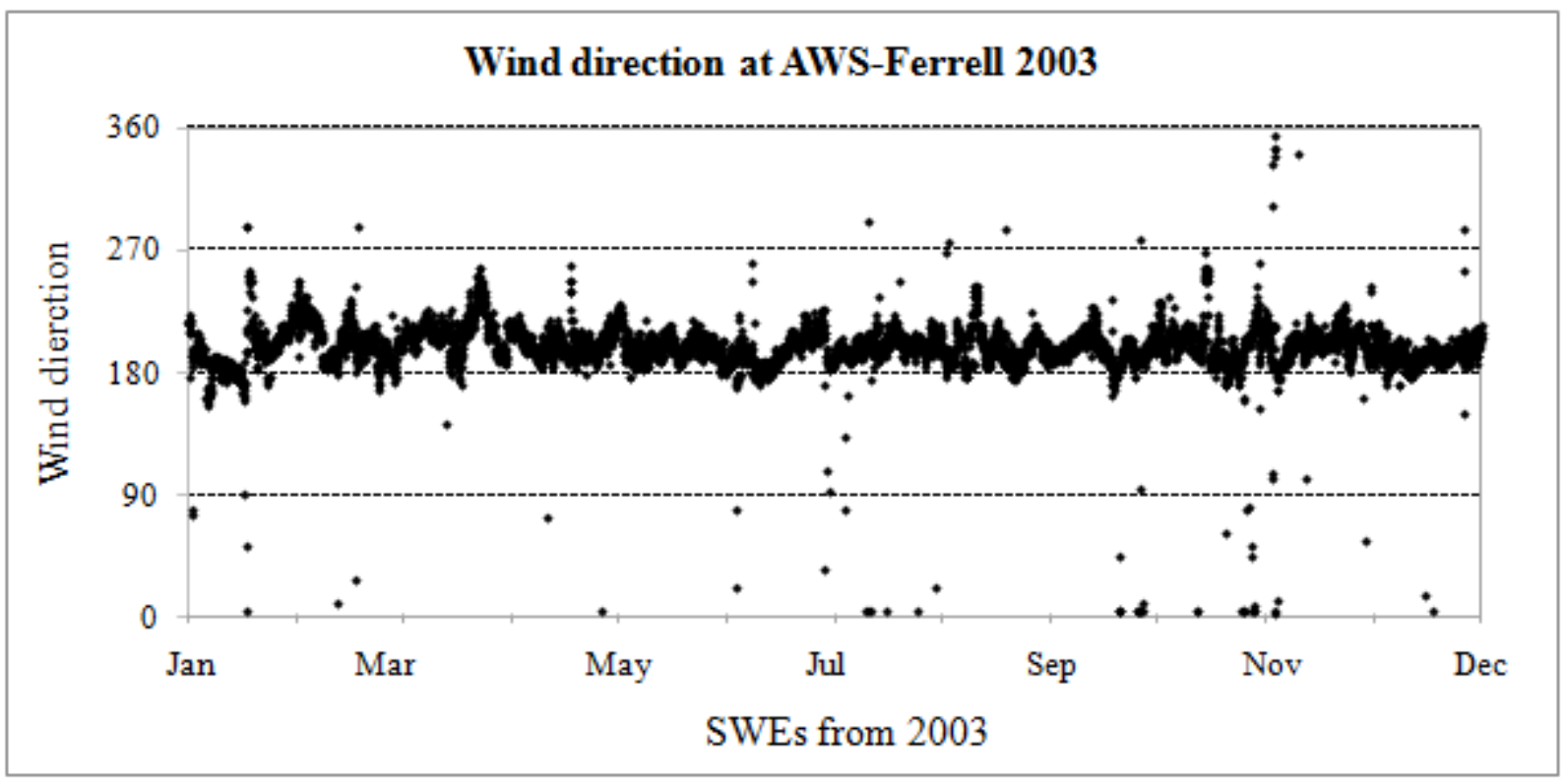

Figure 9(b). The wind directions from AWS Ferrell for the events with wind speed above $10 \mathrm{~ms}^{-1}$. 


\section{Wind speed and MSLP anomaly}

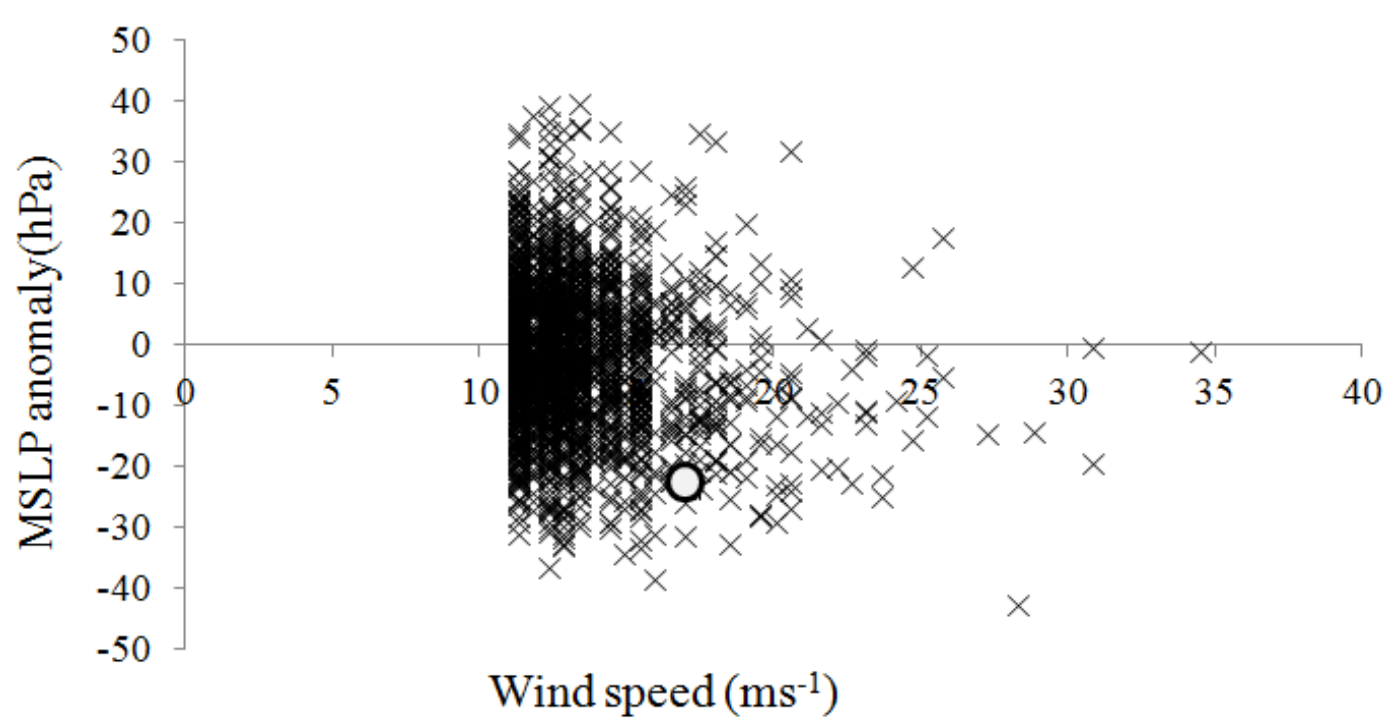

Figure 10(a).Scatter plot of MSLP anomaly against wind speed for all SWEs during the years 1979-2005. (Triangle and circle on the graph denotes selected SWE example on 15 May 2004 and 26 May 1982 respectively)

\section{Wind speed and temperature anomaly}

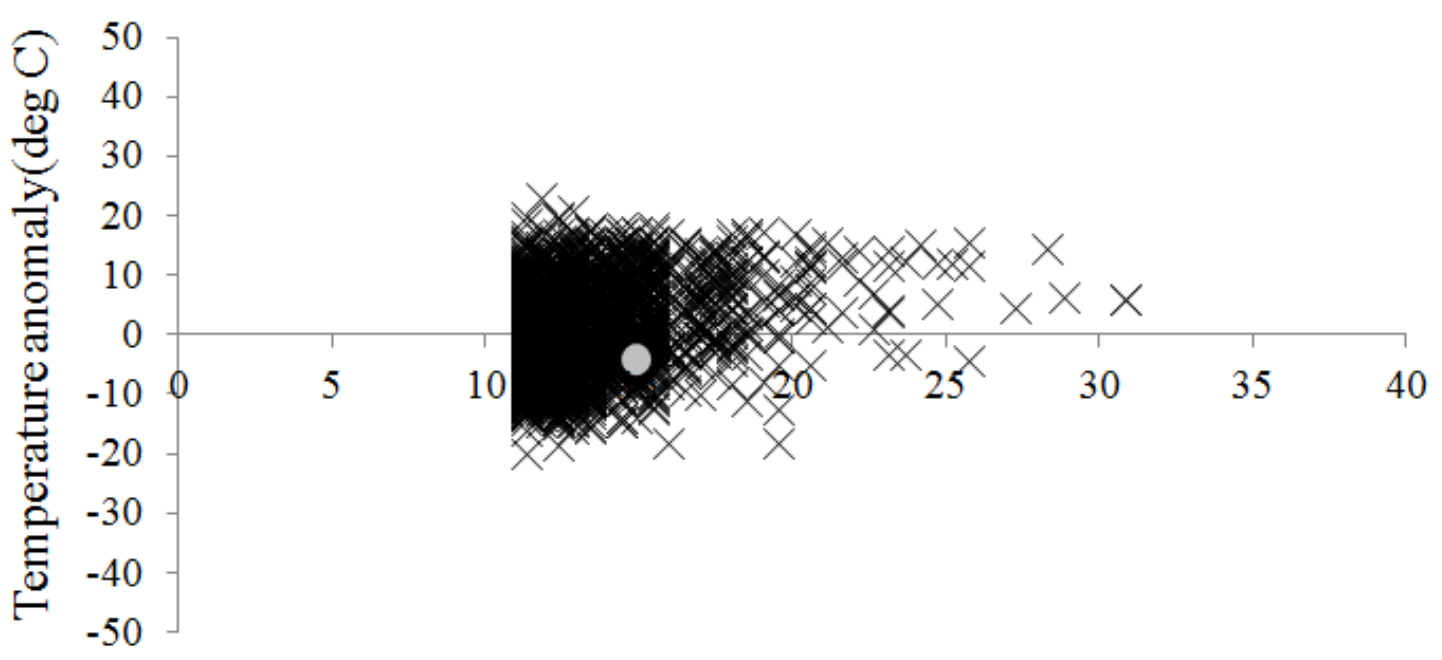

\section{Wind speed $\left(\mathrm{ms}^{-1}\right)$}

Figure 10(b). Scatter plot of temperature anomaly against wind speed for all SWEs during the years 1979-2005. (Triangle and circle on the graph denotes selected SWE example on 15 May 2004 and 26 May 1982 respectively) 


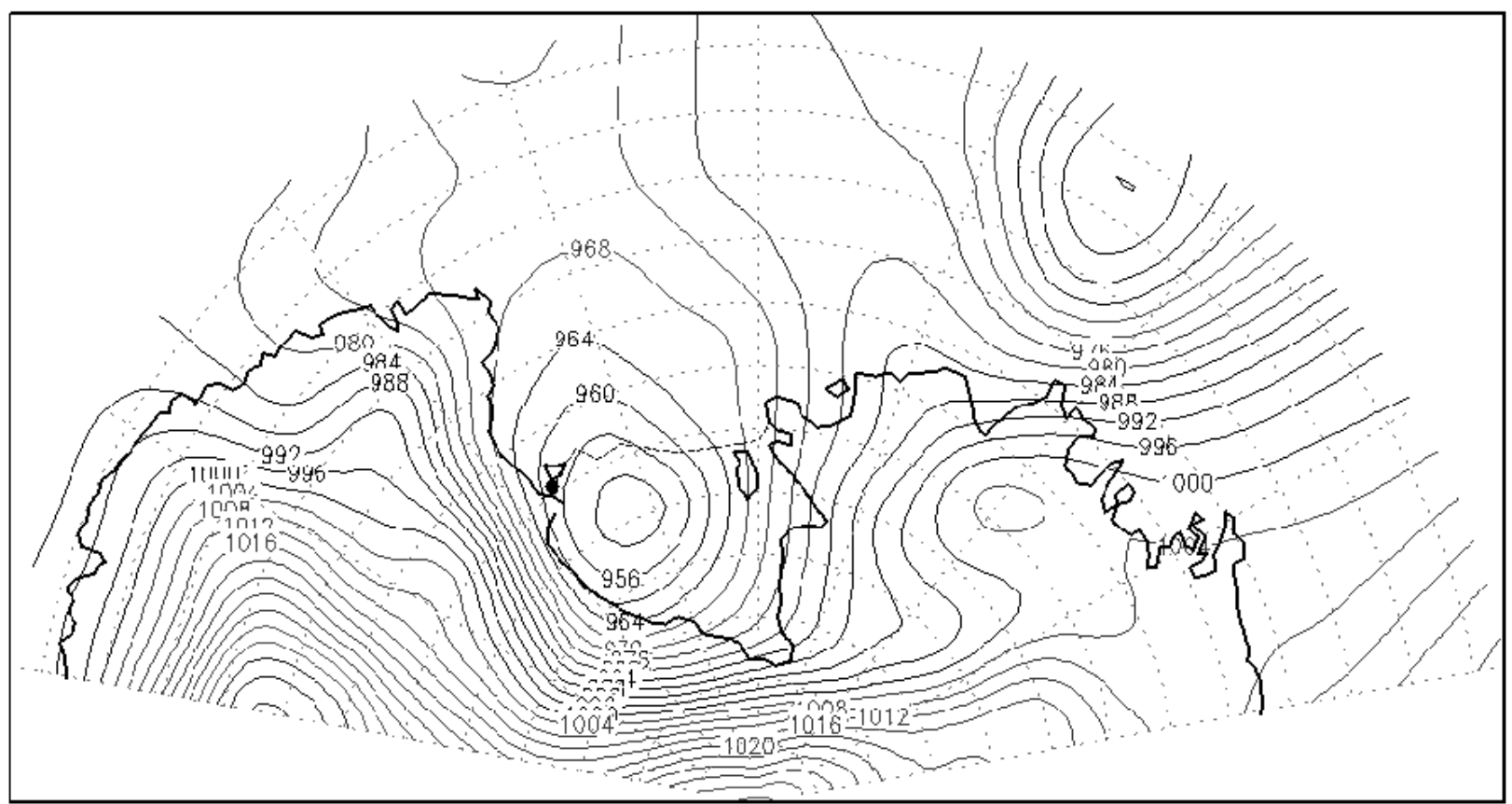

Figure 11(a). The MSLP (hPa) at 1200 UTC 15 May 2004 when McMurdo Station experienced a SWE. The location of McMurdo Station is shown by a black dot. The a contour interval is $4 \mathrm{hPa}$

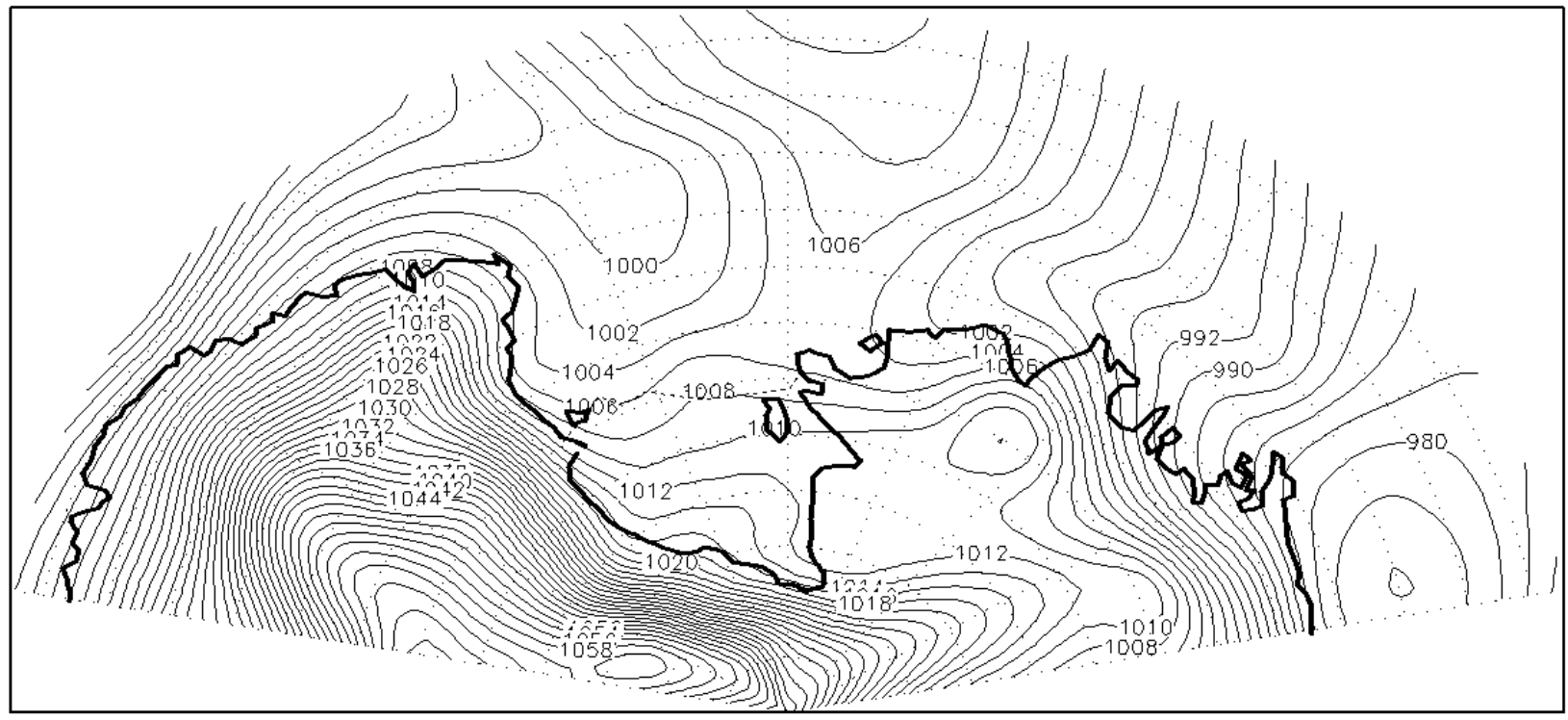

Figure 11(b). The MSLP (hPa) at 0600 UTC 26 May 1982 when McMurdo Station experienced a SWE. The location of McMurdo Station is shown by a black dot. The a contour interval is $2 \mathrm{hPa}$ 


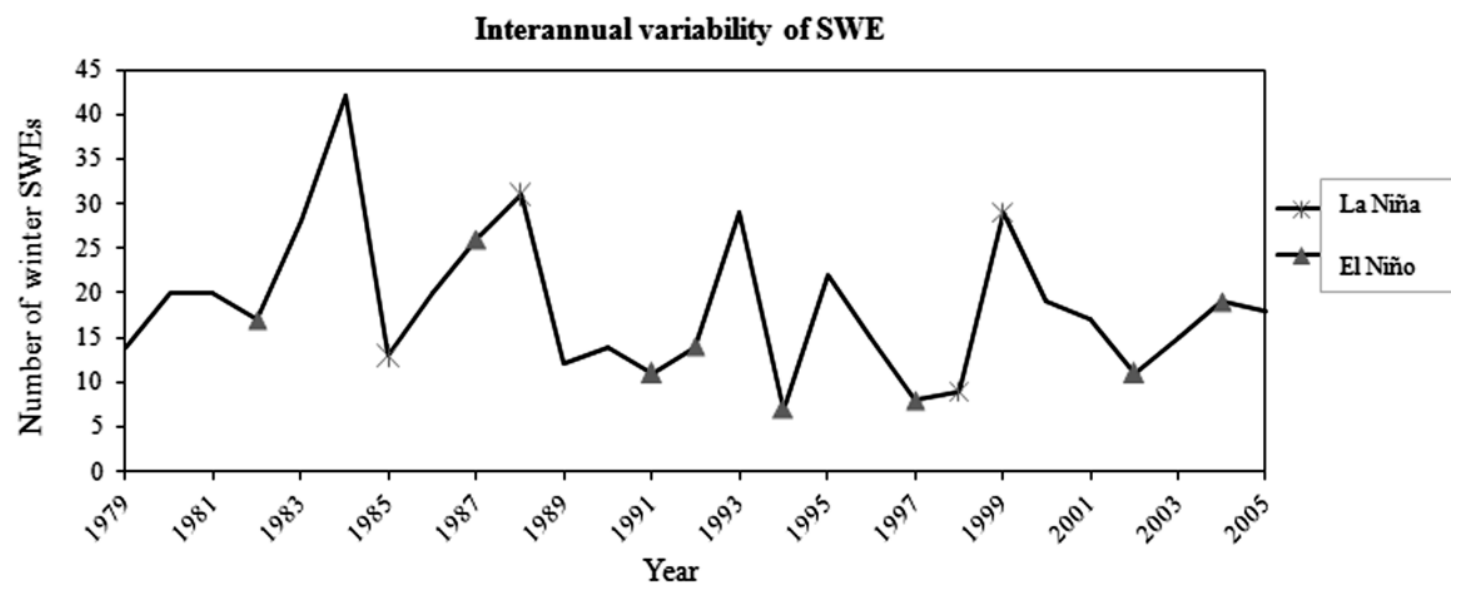

Figure 12. The interannual variability of winter (JJA) SWEs at McMurdo Station from 1979 to 2005 . The El Niño and La Niña years are indicated by triangle and star marker respectively. 


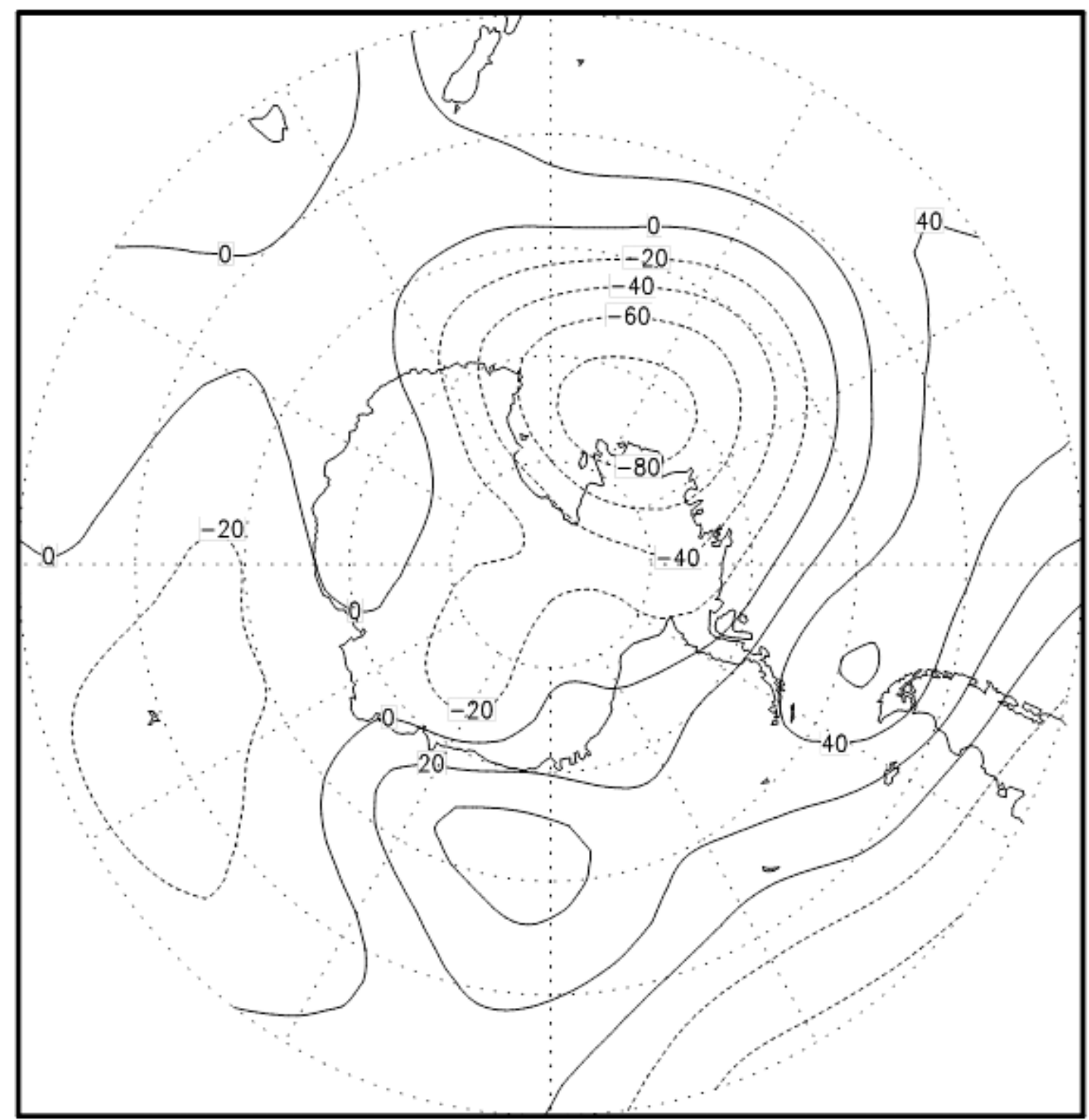

Figure 13. The mean winter (JJA) $500 \mathrm{hPa}$ height anomaly (meters) for 1984 when there were 42 SWEs at McMurdo Station. The location of McMurdo Station is shown by a black dot. 


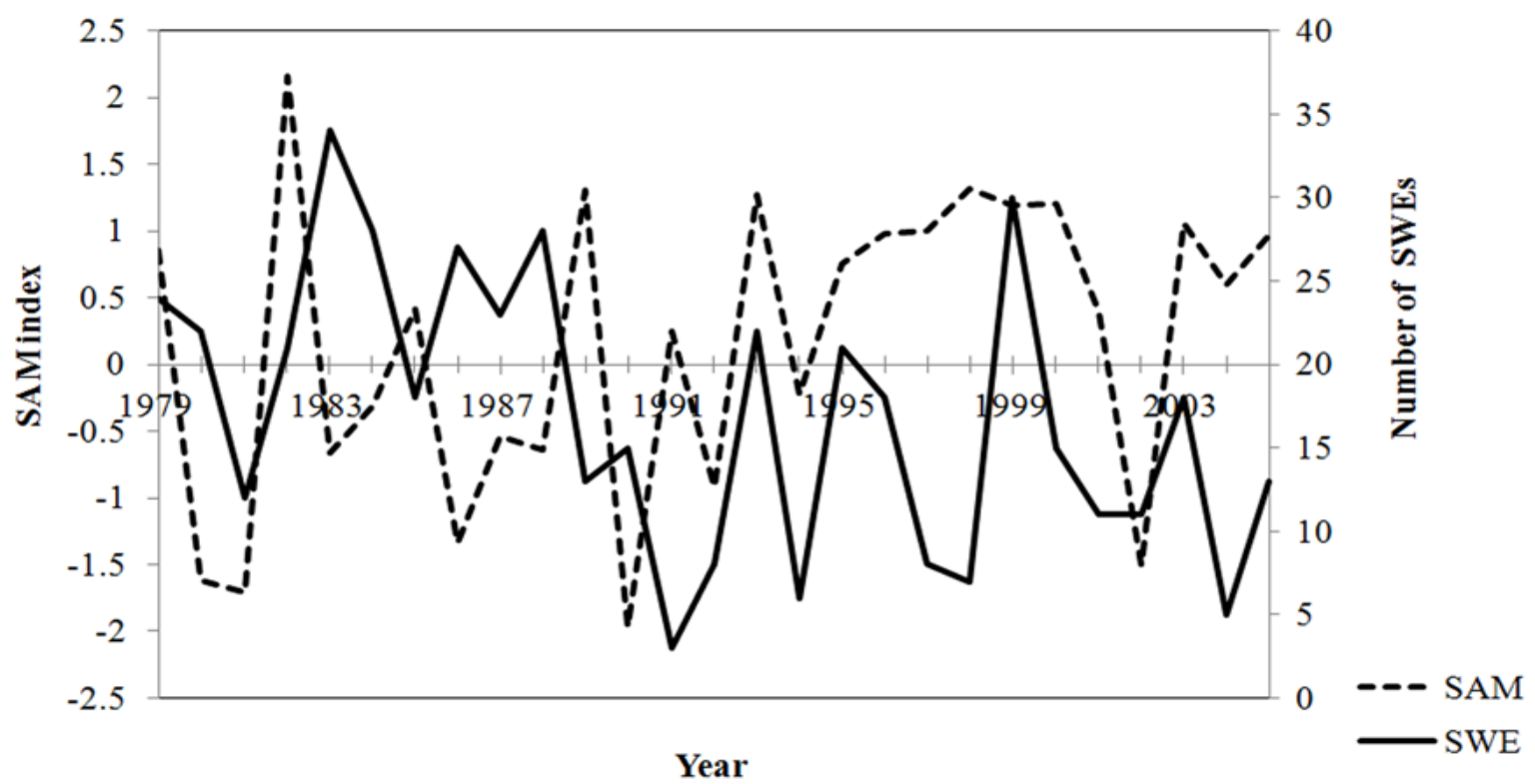

Figure 14. The interannual variability in the number of autumn SWEs for the period 1979-2005 denoted by black line. Also shown is the autumn mean SAM index (dashed line). 


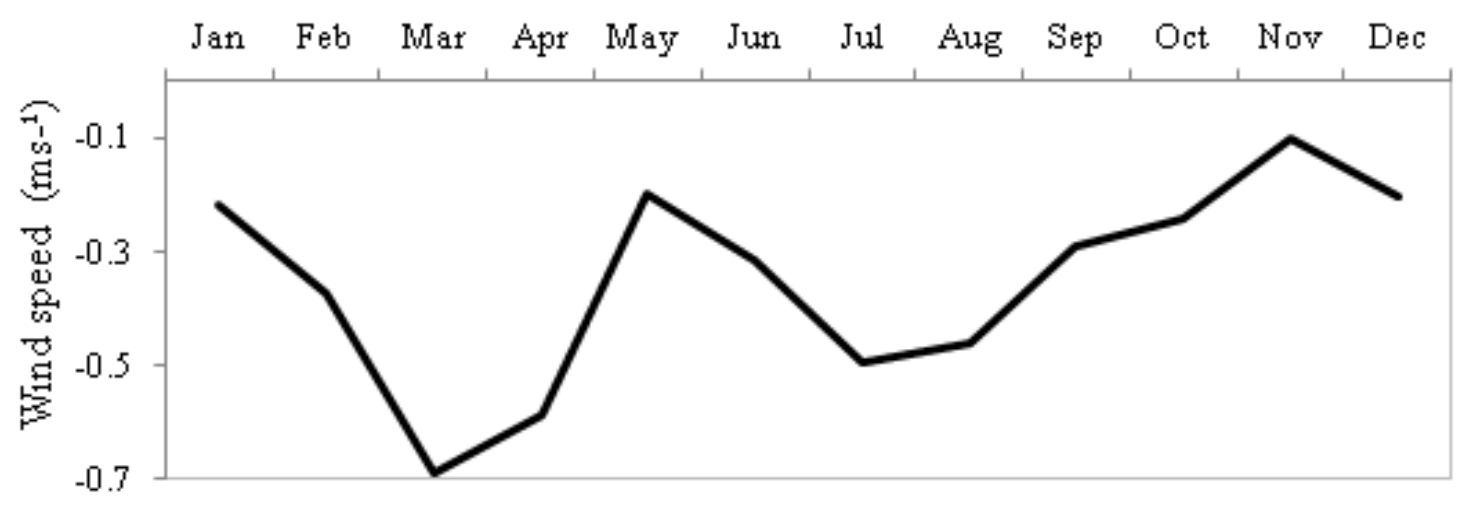

Trend in wind speed (1979-2005)

Figure 15. Long term (1979-2005) trend in the McMurdo Station wind speed in March. 


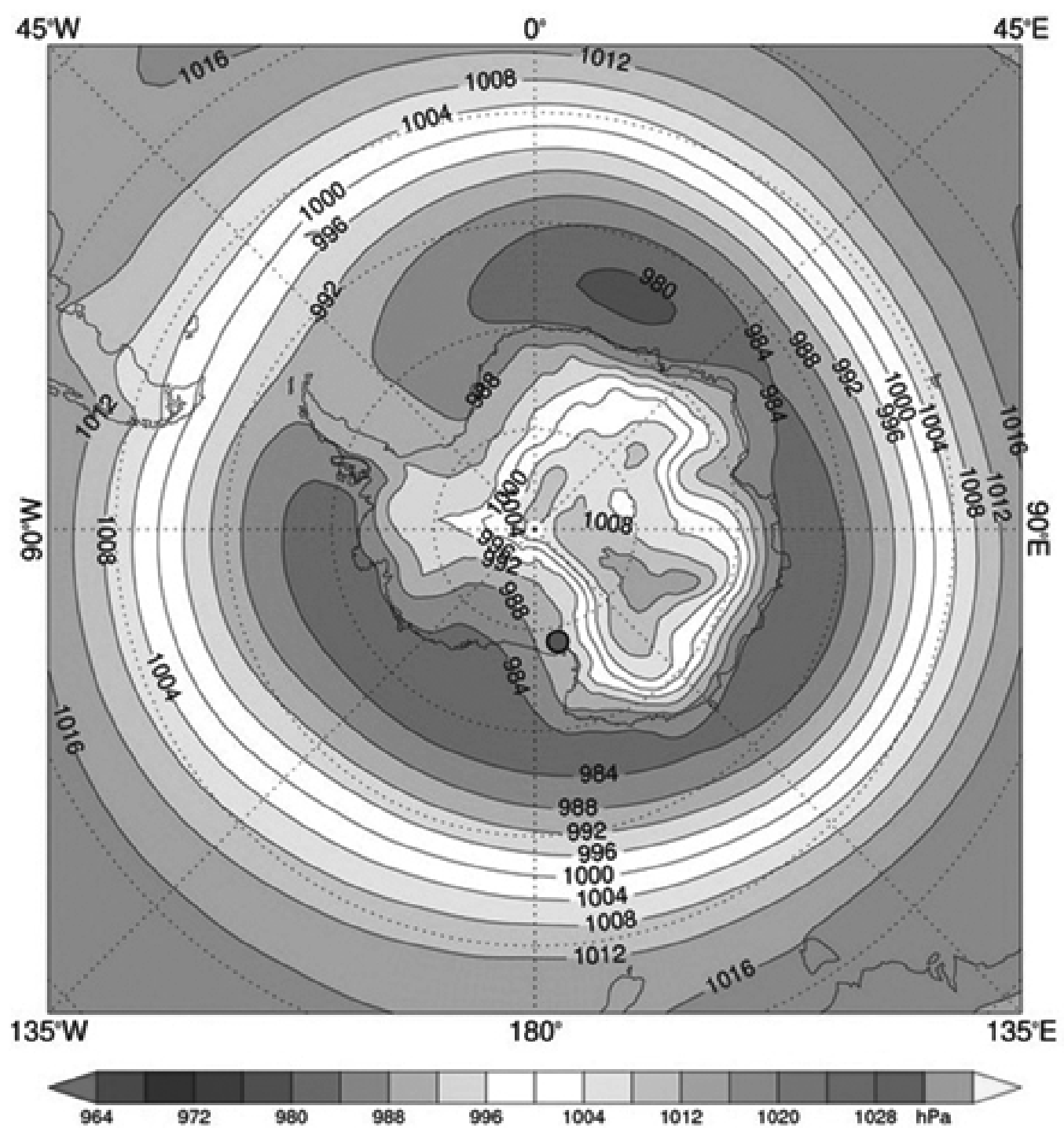

Figure 16.The long term (1979-2005) average MSLP (hPa) for March with a contour interval of $4 \mathrm{hPa}$. The location of McMurdo Station is shown by a black dot. 


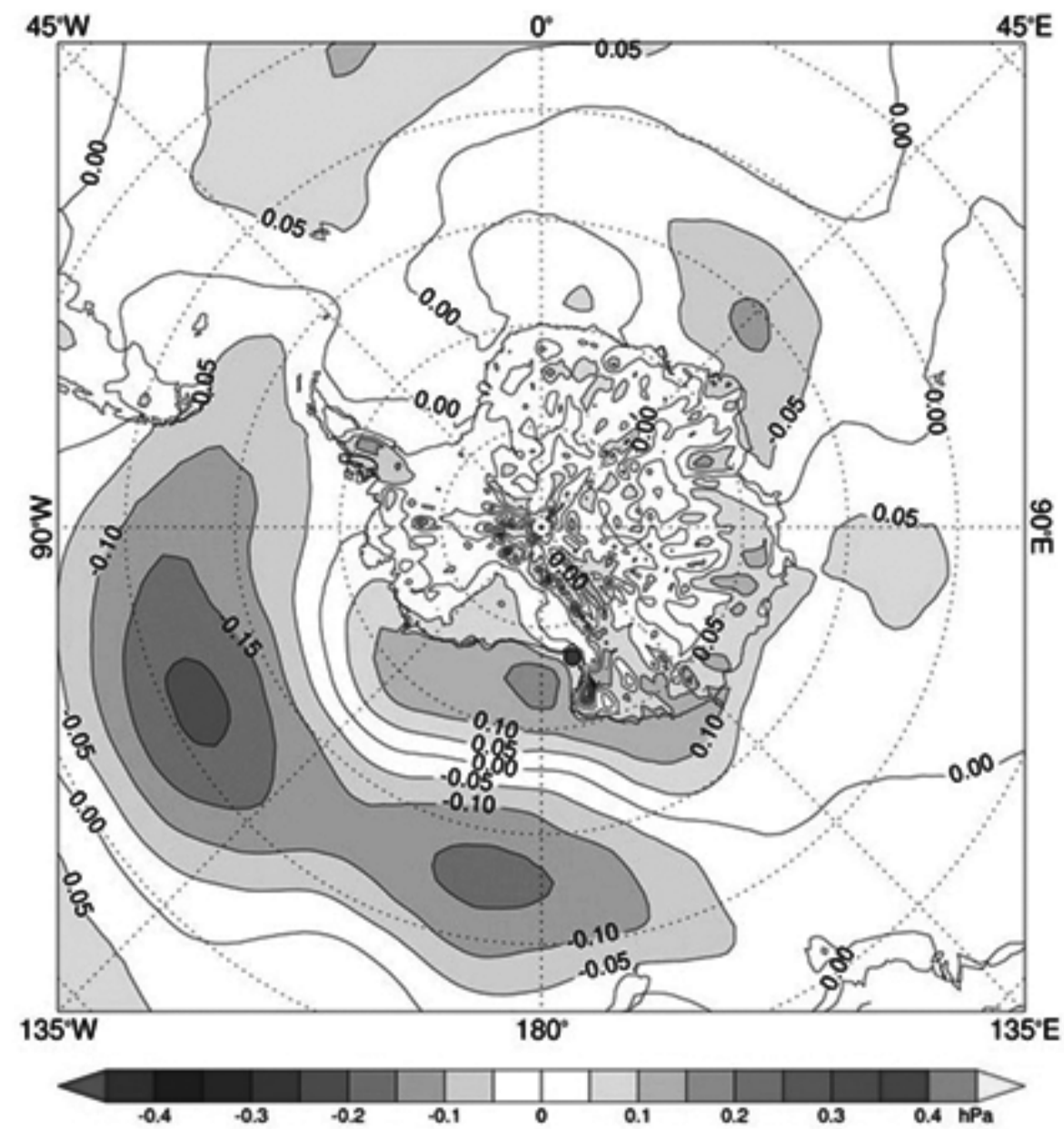

Figure 17. The long term (1979-2005) trend in MSLP (hPa) for March. The location of McMurdo Station is shown by a black dot. 
Number of mean winter SWEs 1979-2005

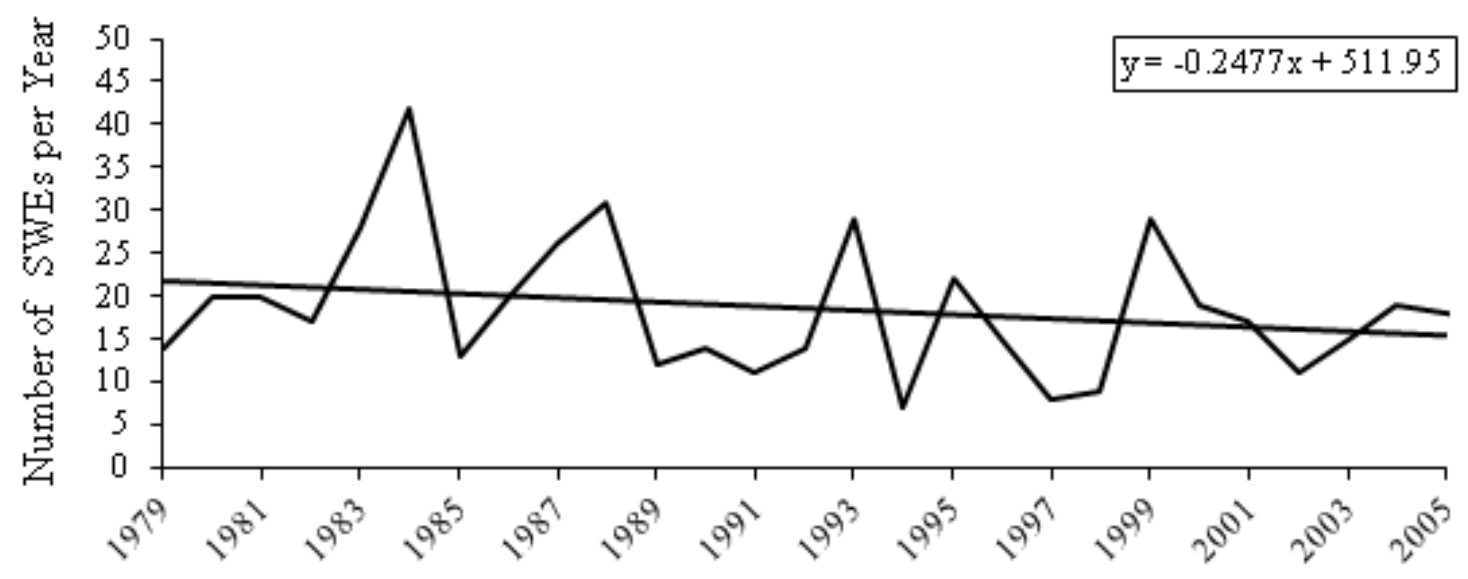

Figure 18. Trend in the number of winter SWEs at McMurdo Station from 1979- 2005. 